\title{
Calibration Variable Selection and Natural Zero Determination for Semispan and Canard Balances
}

\author{
N. Ulbrich* \\ Jacobs Technology Inc., Moffett Field, California 94035-1000
}

\begin{abstract}
Independent calibration variables for the characterization of semispan and canard wind tunnel balances are discussed. It is shown that the variable selection for a semispan balance is determined by the location of the resultant normal and axial forces that act on the balance. These two forces are the first and second calibration variable. The pitching moment becomes the third calibration variable after the normal and axial forces are shifted to the pitch axis of the balance. Two geometric distances, i.e., the rolling and yawing moment arms, are the fourth and fifth calibration variable. They are traditionally substituted by corresponding moments to simplify the use of calibration data during a wind tunnel test. A canard balance is related to a semispan balance. It also only measures loads on one half of a lifting surface. However, the axial force and yawing moment are of no interest to users of a canard balance. Therefore, its calibration variable set is reduced to the normal force, pitching moment, and rolling moment. The combined load diagrams of the rolling and yawing moment for a semispan balance are discussed. They may be used to illustrate connections between the wind tunnel model geometry, the test section size, and the calibration load schedule. Then, methods are reviewed that may be used to obtain the natural zeros of a semispan or canard balance. In addition, characteristics of three semispan balance calibration rigs are discussed. Finally, basic requirements for a full characterization of a semispan balance are reviewed.
\end{abstract}

\section{Nomenclature}

$\begin{array}{ll}A F & =\text { axial force } \\ D, D^{\prime} & =\text { distances describing the location of the normal force that acts on a semispan balance } \\ D_{\max } & =\text { largest rolling moment arm } \\ D_{\min } & =\text { smallest rolling moment arm } \\ D_{1}, D_{2}, D_{3} & =\text { rolling moment arm choices of a semispan balance calibration rig } \\ d_{,}, d^{\prime} & =\text { distances describing the location of the axial force that acts on a semispan balance } \\ d_{\max } & =\text { largest yawing moment arm } \\ d_{\min } & =\text { smallest yawing moment arm } \\ d_{1}, d_{2}, d_{3} & =\text { yawing moment arm choices of a semispan balance calibration rig } \\ \mathbf{i} & =\text { coordinate axis that indicates the direction of the axial force } \\ \mathbf{j} & =\text { coordinate axis that indicates the direction of the side force } \\ \mathbf{k} & =\text { coordinate axis that indicates the direction of the normal force } \\ N F & =\text { normal force } \\ P M & =\text { pitching moment } \\ q, q^{\prime} & =\text { distances describing the location of the normal force that acts on a canard balance } \\ r A F & =\text { electrical output of the axial force gage } \\ r N F & =\text { electrical output of the normal force gage } \\ r P M & =\text { electrical output of the pitching moment gage } \\ r R M & =\text { electrical output of the rolling moment gage } \\ r Y M & =\text { electrical output of the yawing moment gage } \\ \end{array}$

* Aerodynamicist, Jacobs Technology Inc. 


$$
\begin{array}{ll}
R M & =\text { rolling moment } \\
S F & =\text { side force } \\
Y M & =\text { yawing moment } \\
\Delta & =\text { rolling moment arm of the side force } \\
\delta & =\text { yawing moment arm of the side force } \\
\delta A F & =\text { tare load in axial force direction } \\
\delta N F & =\text { tare load in normal force direction } \\
\mu & =\text { dihedral angle of an airplane wing } \\
\varphi & =\text { sweepback angle of an airplane wing }
\end{array}
$$

\section{Introduction}

Design, calibration, and use of semispan and canard wind tunnel balances are unique because they measure aerodynamic loads on only one half of a lifting surface. Suitable independent calibration variable sets have to be identified that allow for a complete characterization of the physical behavior of these balance types. In addition, as tare load iterations are required for the final regression analysis of semispan balance calibration data, reliable procedures have to be defined that can be used for the determination of the natural zeros of the balance (see Ref. [1] for the description of the tare load iteration process).

Unfortunately, only a limited amount of information is available in the open literature that may be used to better understand (i) the calibration variable selection and (ii) the natural zero determination of semispan and canard balances. Therefore, the author decided to look at these two topics in more detail. Results of his review may be useful for a general evaluation of both semispan and canard balance calibration data sets.

The next section of the paper describes a first principles analysis of semispan and canard balance loads that helps identify possible calibration variable choices. Then, two combined load diagrams are discussed that are unique to semispan and canard balances. They illustrate an important "hidden" connection between the balance calibration data and the geometry of the tested wind tunnel model or lifting surface. In addition, three methods are reviewed that may be used to obtain natural zeros for semispan and canard balances. Then, examples of semispan balance calibration rigs are discussed so that the connection between calibration variable choice, calibration hardware, and load schedule design limitations can be illustrated. Finally, requirements for a full characterization of a 5-component semispan balance are listed.

\section{Calibration Variable Selection}

In principle, the selection of the independent variables for the calibration of a semispan or canard balance is determined by the loads that the balance will see during a wind tunnel test. Therefore, it is necessary to analyze the anticipated balance forces and moments in detail. Semispan and canard balances have many characteristics in common. Both experience loads that act on only one half of a wing or lifting surface. In addition, most semispan and canard balances are single-piece balances, i.e., they are machined out of a single piece of metal. Consequently, neither a semispan nor a canard balance should have bi-directional characteristics. In other words, their gage outputs should not show an asymmetry that depends on the sign of the load when a primary gage output is plotted versus the corresponding primary gage load.

A resultant normal force is generated somewhere on the lifting surface that is attached to the semispan or canard balance during a wind tunnel test. Consequently, the resultant normal force will generate both a rolling and pitching moment about the roll and pitch axis of the balance. A user of a semispan balance is also interested in the resultant axial force and yawing moment as an extended high-lift system, winglets, and propulsion simulators can generate large axial loadings on a wing. Therefore, a typical semispan balance is a five-component balance. Canard balances, on the other hand, measure only three load components that are a subset of the load set that the five-component semispan balance experiences.

Six-component semispan balances also exist that measure the side force component in addition to the normal force, axial force, and related moments. However, six-component semispan balances are not discussed in the current paper as any side force acting on a "true" semispan model configuration in a wind tunnel is cancelled by the corresponding side force that acts on the configuration's image. 
For the current investigations it was decided to first look at loads that act on a semispan balance. In general, a semispan balance experiences the normal force, axial force, and all related moments that act on a wind tunnel model. In fact, the normal force, i.e., $N F$, and the axial force, i.e., $A F$, are the first and second independent calibration variable of the semispan balance.

During a wind tunnel test neither the normal force nor the axial force will necessarily act on the pitch axis of the balance. The normal force will be located somewhere in the plane that is defined by the pitch axis $\mathbf{j}$ and roll axis $\mathbf{i}$ of the balance (see Fig. 1a). Its position in the $\mathbf{i}-\mathbf{j}-$ plane can be described by the distances $D$ and $D^{\prime}$. Similarly, the axial force will be located somewhere in the plane that is defined by the pitch axis $\mathbf{j}$ and the yaw axis $\mathbf{k}$ of the balance (see Fig. 1b). Its position in the $\mathbf{j}-\mathbf{k}-$ plane can be described by the distances $d$ and $d^{\prime}$.

The two sets of distances required for the description of the position of the normal and axial force relative to the balance moment center could indicate to a casual observer that the characterization of the behavior of a semispan balance would require six independent calibration variables. Fortunately, this is not the case. It is possible, after the introduction of two force couples, to shift both the normal and axial forces to the pitch axis of the balance without changing the resultant loads that act on the balance.

The shift of the two force components is shown in Fig. 2 and Fig. 3. The force shift naturally leads to the introduction of the pitching moment, i.e., $P M$, as the third calibration variable of the semispan balance. The pitching moment $P M$ replaces the two geometric distances $D^{\prime}$ and $d^{\prime}$ as independent calibration variables as the balance will always superimpose the pitching moment contributions from the shifted resultant normal and axial forces.

Figure 4a summarizes the five independent variables that are needed for a complete characterization of a semispan balance. The five calibration variables are:

$$
\text { Semispan Balance } \Longrightarrow N F, A F, P M, D, d
$$

For convenience, the two distances $D$ and $d$ are traditionally replaced by the related moments. The distance $D$ is proportional to the rolling moment $R M$. The distance $d$ is proportional to the yawing moment $Y M$. Then, the five independent calibration variables of the semispan balance are:

$$
\text { Semispan Balance } \Longrightarrow N F, A F, \quad P M, \quad R M, Y M
$$

Similarly, Fig. 4b summarizes the three independent variables that are needed for a complete characterization of a canard balance (the axial force and the related yawing moment are of no interest to a user of a canard balance). The three calibration variables are:

$$
\text { Canard Balance } \Longrightarrow N F, q, q^{\prime}
$$

Again, the distances $q$ and $q^{\prime}$ in the $\mathbf{i}-\mathbf{j}-$ plane can be replaced by the related moments. The distance $q$ is proportional to the rolling moment $R M$. The distance $q^{\prime}$ is proportional to the pitching moment $P M$. Then, the three independent calibration variables of the canard balance are:

$$
\text { Canard Balance } \Longrightarrow N F, P M, R M
$$

Combined load diagrams can be developed for the rolling and yawing moment when they are plotted versus the normal and axial force. These diagrams are discussed in the next section of the paper.

\section{Combined Load Diagram}

The combined load diagram of balance calibration data is a convenient way to interpret combined load plots that can be generated for any calibration data set. The diagram was first introduced in 2010 for force, moment, and direct-read balances (see Ref. [2]). It is possible to extend the idea of a combined load diagram to semispan and canard balances. In this case, the combined load diagrams of the (i) rolling moment and normal force combination and of the (ii) yawing moment and axial force combination are important. They illustrate basic connections between the rolling/yawing moment arms used during the balance calibration and the geometry of a semispan model or lifting surface that is attached to the balance. 
First, the diagram of the rolling moment and normal force combination is discussed. The diagram is shown in Fig. 5a. Six conclusions can be drawn from Fig. 5a: (1) calibration points of a left wing semispan model or left control surface appear in the first and third quadrant; (2) calibration points of a right wing semispan model or right control surface appear in the second and fourth quadrant; (3) calibration points of a balance calibrated for a left wing model will appear inside of two green sectors in the first and third quadrant; (4) the sectors are bound by lines that correspond to the smallest and largest rolling moment arm that was applied during the balance calibration; (5) points located in the yellow regions are outside of the region that is defined by the load envelope of the balance calibration for a left wing model; (6) the distances of the metric flange of the balance and of the wind tunnel boundary from the balance moment center limit the physically possible moment arms in the wind tunnel.

Similarly, the diagram of the yawing moment and axial force combination can be constructed. The diagram is depicted in Fig. 5b. Again, six conclusions can be drawn: (1) calibration points of a left wing semispan model or left control surface appear in the second and fourth quadrant; (2) calibration points of a right wing semispan model or right control surface appear in the first and third quadrant; (3) calibration points of a balance calibrated for a left wing model will appear inside of two green sectors in the second and fourth quadrant; (4) the sectors are bound by lines that correspond to the smallest and largest yawing moment arm that was applied during the balance calibration; (5) points located in the yellow regions are outside of the region that is defined by the load envelope of the balance calibration for a left wing model; (6) the distances of the metric flange of the balance and of the wind tunnel boundary from the balance moment center limit the physically possible moment arms in the wind tunnel. Now, the calibration points of a balance calibrated for a left wing model appear in the second and fourth quadrant. This quadrant switch from Fig. 5a to Fig. 5b is the result of the load sign convention that is historically used in the aerospace industry in North America (see Ref. [1], p. 3, for a description of the sign convention).

Ideally, the expected rolling and yawing moment arms during a wind tunnel test of a semispan model should be located inside of the green sectors that are shown in Fig. 5a and Fig. 5b. Then, the balance is used inside of its load envelope and potential extrapolation is avoided. Therefore, as a rule of thumb, the author recommends to use $50 \%$ of the semispan of the largest-size semispan model as a dimension to define the upper limit of the rolling and yawing moment arms that should to be applied during the calibration. The physical lower limit of the rolling and yawing moment arm in the wind tunnel is the distance between the balance moment center and the surface of the metric flange of the balance (see Figs. 5a, 5b). This value is 9 inches for NASA's MC400 semispan balance. The physical lower limit could be selected as the smallest rolling or yawing moment arm that is used during the calibration of the balance. Sometimes this value cannot be applied because of hardware limitations. In that case, the author recommends to use $20 \%$ of the semispan of the smallest-size model as a dimension to define the lower limit of the rolling and yawing moment arms assuming that calibration hardware can be designed to support this choice. The $20 \%$ and $50 \%$ limits, of cause, are compromises because, for cost reasons, one has to limit the moment arm range. There is nothing wrong with the use of smaller or larger moment arms as long as (i) loads can be applied at the chosen moment arms and (ii) load capacities of the balance are not exceeded.

\section{Side Force Effects}

A user of a 5-component semispan balance may get additional insight about the balance loads by monitoring the two combined load diagrams, i.e., Fig. 5a and Fig. 5b, during a wind tunnel test. It is only necessary to plot corresponding load combinations for the wind tunnel data points. It is important to emphasize that the two combined load diagrams were derived from balance calibration data assuming that the side force is either zero or located on the pitch axis of the balance. These two assumptions are no longer valid if a semispan model is tested in a wind tunnel using a 5-component semispan balance.

Different semispan model characteristics influence both location and magnitude of the side force that acts on the balance. The model's center of gravity may not be on the pitch axis of the balance. Then, assuming that the model is mounted on the test section floor, the model's weight may cause a side force that is not on the pitch axis of the balance. The dihedral angle and the sweepback angle of the model's wing may be different from zero. These two parameters of the wing geometry also shift the location of the side force relative to the pitch axis of the balance (for more detail see Fig. 5c). In addition, the magnitude of

American Institute of Aeronautics and Astronautics 
the side force may change as a function of the angle of attack of the model. All these characteristics cause a side force that contributes to the rolling and yawing moment measurements of the balance.

The influence of the model's side force is "indirectly" contained in the electrical outputs of the rolling and yawing moment gages. The rolling moment gage, for example, cannot distinguish if a normal force or a side force causes its outputs. Similarly, the yawing moment gage cannot distinguish if an axial force or a side force is responsible for its outputs. The regression models of the calibration data still correctly predict the "hidden" rolling and yawing moment contributions of the side force because the connection between the moments and corresponding primary gage outputs is highly linear. However, the rolling and yawing moments were not applied in this way during the calibration of the balance. Therefore, wind tunnel data points plotted for a left wing model in the combined load diagrams (Figs. 5a, 5b) may be shifted to regions that are labeled "right wing", "balance interior", or "tunnel exterior."

The combined load diagram of the yawing moment versus the axial force, i.e., Fig. 5b, is expected to be more sensitive to the influence of the model's side force. This conclusion can be drawn from the fact that the normal force acting on a semispan model is one order of magnitude larger than the axial force for the majority of wind tunnel test conditions. Then, the side force and the axial force are potentially closer to being of similar magnitude as (i) the absolute value of the ratio between the side force and the axial force is much greater than the absolute value of the ratio between the side force and the normal force and (ii) the absolute value of the ratio between the side force and the normal force is much smaller than one.

\section{Left Wing Model versus Right Wing Model}

Situations are conceivable when a right wing model may used on a semispan balance that was originally calibrated for a left wing model (and vice versa). Fortunately, no new calibration of the balance is required in this case. It is only necessary to apply load transformations that take the load sign convention of Ref. [1] into account. The following transformations can be derived for the normal force, yawing moment, and pitching moment in the balance axis system by comparing the corresponding load components that are shown in Fig. 6 (right $\equiv$ right wing, left $\equiv$ left wing):

$$
N F_{\text {right }}=-N F_{\text {left }} ; Y M_{\text {right }}=-Y_{\text {left }} ; P M_{\text {right }}=-P M_{\text {left }}
$$

The axial force and the rolling moment, on the other hand, do not have to be transformed as the sign of these components does not change as far as the sign convention of the semispan balance loads in the balance axis system is concerned. Therefore, we get:

$$
A F_{\text {right }}=A F_{\text {left }} ; R M_{\text {right }}=R M_{\text {left }}
$$

The transformations of the normal force, yawing moment, and pitching moment, of cause, assume that (i) the balance installation and its orientation relative to the test section are not changed when a right wing model instead of a left wing model is tested and that (ii) the normal force, yawing moment and pitching moment were calibrated symmetrically over the positive and negative load range of the balance (e.g., from $-100 \%$ capacity to $+100 \%$ capacity).

\section{Natural Zeros}

The regression analysis of semispan balance calibration data often requires a tare load iteration in order to develop an accurate regression model that can be used for the prediction of aerodynamic loads during a wind tunnel test (see Ref. [1] for a discussion of the tare load iteration process). In principle, the tare load iteration process connects balance loads to an absolute load datum that is defined by the natural zeros. First, the tare load iteration uses the natural zeros and other information to numerically estimate the weight of the metric part of the balance and of other calibration hardware pieces. Then, the tare load estimates are applied to the original loads. The resulting tare corrected load set is the load set that is used for the final regression analysis of the semispan balance calibration data. It is also the load set that the balance would have experienced in "zero gravity."

The description of the orientation of the balance relative to the gravitational acceleration is meaningless in "zero gravity." Therefore, it is critical to perform a tare load iteration during the analysis of semispan

American Institute of Aeronautics and Astronautics 
balance calibration data in order to make the loads independent of the direction of the gravitational acceleration. Consequently, assuming that a data reduction matrix was derived from a tare corrected load set, it is, for example, possible to use a semispan balance during a wind tunnel test in an orientation that has the pitch axis parallel to the gravitational acceleration even though the balance may have been calibrated in an orientation that had the pitch axis perpendicular to the gravitational acceleration. In other words the orientation of the semispan balance during its calibration does not have to match the orientation of the semispan balance during its use in a wind tunnel as long as the regression model of the balance loads was obtained from tare corrected calibration loads.

The tare load iterations can only be performed correctly if the absolute load datum, i.e., the natural zeros of the balance gages, are known. The natural zeros are the electrical outputs of the balance gages in an assumed "weightless" condition. In principle, three different methods can be used to determine the natural zeros of a semispan balance. Basic ideas of these three methods are discussed in Ref. [3] for a force balance. The three methods essentially "average" readings of the gage outputs that are taken at different orientations of the balance relative to the gravitational acceleration. Figure 7 shows the six possible orientations that a semispan or canard balance can have relative to the gravitational acceleration.

Method I, for example, mounts the non-metric part of the balance in a support such that the pitch axis is perpendicular to the gravitational acceleration (see Fig. 8a). Then, the balance is put into the first four orientations that are shown in Fig. 7. The natural zero is simply the arithmetic mean of the outputs that are recorded for the four orientations. The gage outputs of each orientation are caused by the weight of the metric part of the semispan balance (see Fig. 8b).

Method II also mounts the balance such that the pitch axis is perpendicular to the gravitational acceleration (see Fig. 9a). This time, however, the metric part of the balance is attached to the balance support. Then, as before, the balance is put into the first four orientations that are shown in Fig. 7. Again, the natural zero is simply the arithmetic mean of the outputs that are recorded for the four orientations. This time, however, the gage outputs of each orientation are caused by the weight of the non-metric part of the semispan balance (see Fig. 9b).

Method III is the most simple way to obtain the natural zeros of a semispan balance. The balance is simply put in "UP" orientation on a leveled surface (see Fig. 10). The natural zeros are the outputs of the gages in that orientation. In other words - no averaging is needed if Method III is applied.

In 2012 NASA's MC400 semispan balance was calibrated using Triumph Aerospace's Large Load Rig. During the calibration natural zero points according to Method I and Method III above were recorded. The following absolute voltages (normalized by the excitation voltage) were obtained for the five balance gages:

Table 1: Determination of the natural zeros of NASA's MC400 semispan balance.

\begin{tabular}{|c|c|c|c|c|c|}
\hline ORIENTATION & $r N F, \mu V / V$ & $r P M, \mu V / V$ & $r Y M, \mu V / V$ & $r R M, \mu V / V$ & $r A F, \mu V / V$ \\
\hline 0 & -34.3 & +397.2 & +86.0 & -100.1 & +22.5 \\
90 & -24.9 & +397.7 & +88.2 & -99.8 & -10.9 \\
180 & -15.4 & +397.5 & +85.9 & -99.1 & +22.5 \\
270 & -24.8 & +396.6 & +83.7 & -99.4 & +55.8 \\
\hline arithmetic mean (Method I) & -24.8 & +397.2 & +86.0 & -99.6 & +22.5 \\
\hline "UP" (Method III) & -25.1 & +394.9 & +86.1 & -99.7 & +21.9 \\
\hline
\end{tabular}

It is concluded, after comparing the averaged outputs of Method I with the readings of Method III, that the maximum difference between the estimates is about $2 \mu \mathrm{V} / \mathrm{V}$. This result indicates an excellent agreement of the natural zero estimates that are obtained by applying the two methods.

The four natural zero points obtained for Method I and listed in Table 1 above have another use when it comes to performing a validation of the predictive capability of the data reduction matrix that is derived from the calibration data. A weight estimate of the metric part of the balance can be determined by using (i) the differences of the four measured gage outputs relative to the natural zeros and (ii) the data reduction matrix of the calibration data as input for a load calculation. This theoretical estimate of the weight of the 
metric part of the balance may be compared with an alternate weight estimate that can be obtained from the volume and material density of the metric part of the balance. This comparison of two independent estimates of the weight of the metric part of the MC400 semispan balance was performed. The numerical estimate of the weight obtained from the four natural zero data points of Method I was 421 [lbs]. The theoretical value based on an analysis of the volume of the metric part of the balance was $448[l b s]$. The difference between the two estimates is only $27[l b s]$ or $0.07 \%$ of the normal force capacity of the MC400.

The determination of the natural zeros of a canard balance is physically easier when compared with a semispan balance. A canard balance is small, its weight is insignificant, and it can easily be handled. NASA's MC400 semispan balance, in contrast, has a total weight of about 1300 [lbs]. Method I or Method III can be applied to a canard balance (see Fig. 11). Again, Method III is the most simple technique as the natural zeros can directly be read using a single orientation of the balance.

\section{Semispan Balance Calibration Rig Examples}

Different approaches can be used to apply specific calibration load combinations that are needed for the characterization of a 5-component semispan balance. In principle, a very rigid calibration rig structure is needed so that load combinations can accurately be applied while minimizing the time needed for both alignment of the balance and the load vectors. The magnitude of calibration loads, calibration rig space requirements, and construction cost are usually the driving factors behind the final lay-out of a calibration rig for a semsipan balance. In addition, the calibration rig needs to be capable of applying combinations of normal force (rolling moment), axial force (yawing moment), and pitching moment simultaneously as a 5-component semispan balance will mostly experience simultaneous combinations of all five load components during a typical wind tunnel test. This unique characteristic of the use of a semispan balance is caused by the fact that a typical transonic semispan model wing has both significant sweepback and dihedral angles. Therefore, both the resultant normal force and the resultant axial force will be located along two lines that almost never intersect the pitch axis of the semispan balance.

Examples of three different calibration rigs are discussed in this section in order to highlight advantages and disadvantages of different calibration rig designs. Table 2 below summarizes important characteristics of the three calibration rig examples.

Table 2: Comparison of semispan balance calibration rig design characteristics.

\begin{tabular}{|c|c|c|c|c|c|}
\hline $\begin{array}{l}\text { CALIBRATION } \\
\text { RIG DESIGN }\end{array}$ & $\begin{array}{l}\text { BALANCE LOAD } \\
\text { APPLICATION }\end{array}$ & $\begin{array}{l}\text { PITCH AXIS } \\
\text { ORIENTATION }\end{array}$ & $\begin{array}{l}\text { BALANCE } \\
\text { EXAMPLE }\end{array}$ & $\begin{array}{l}\text { NORMAL AND AXIAL } \\
\text { FORCE CAPACITIES }\end{array}$ & $\begin{array}{l}\text { TARE LOADS OF } \\
\text { RIG [\% of capacity] }\end{array}$ \\
\hline $\begin{array}{l}\text { NASA LaRC's Rig } \\
\text { (see Fig. 12) }\end{array}$ & $\begin{array}{l}\text { gravity weights } \\
\text { and lever arms }\end{array}$ & $\begin{array}{l}\text { perpendicular to } \\
\text { gravity vector }\end{array}$ & NTF117S & $\begin{array}{c}N F=12,000[l b s] \\
A F=1,800[l b s]\end{array}$ & $\begin{array}{c}\delta N F \approx 16 \% \\
\delta A F \ldots \text { unknown }\end{array}$ \\
\hline $\begin{array}{l}\text { Triumph's Rig (LLR) } \\
\text { (see Figs. 13a to } 13 \mathrm{~g} \text { ) }\end{array}$ & $\begin{array}{c}\text { hydraulic actuators } \\
\text { and lever arms }\end{array}$ & $\begin{array}{l}\text { perpendicular to } \\
\text { gravity vector }\end{array}$ & MC400 & $\begin{array}{c}N F=40,000[l b s] \\
A F=8,000[l b s]\end{array}$ & $\begin{array}{l}\delta N F \approx 5 \% \\
\delta A F \approx 23 \%\end{array}$ \\
\hline $\begin{array}{l}\text { Hypothetical Rig } \\
\text { (see Figs. 14a, 14b) }\end{array}$ & $\begin{array}{c}\text { hydraulic actuators } \\
\text { and lever arms }\end{array}$ & $\begin{array}{l}\text { parallel to } \\
\text { gravity vector }\end{array}$ & - & - & $\begin{array}{l}\delta N F=0 \% \\
\delta A F=0 \%\end{array}$ \\
\hline
\end{tabular}

Figure 12 shows NASA's NTF117S semispan balance in a calibration rig that is currently in use at NASA Langley Research Center. The NTF117S balance is a medium size balance. It has a normal force capacity of 12,000 [lbs] and an axial force capacity of 1,800 [lbs]. Therefore, gravity weights can be used for its calibration. Gravity weights have the advantage that the force vectors can easily be aligned with the direction of the gravitational acceleration. However, for complex combined loadings or larger capacity balances, space requirements for a gravity-weight based calibration rig increase significantly and the handling of gravity weight stacks can also become difficult. Systematic errors in the calibration data also grow as the complexity of the combined loadings increases. In addition, because the balance is mounted such that its pitch axis is perpendicular to the gravitational acceleration, the tare loads caused by the calibration hardware alone can be large. For example, the tare load of the calibration equipment (i.e., moment arm, yoke assembly, and balance adapter) including the metric part of the balance of the NTF117S balance was 
estimated to be close to 2,000 [lbs] (16\% of balance's normal force capacity).

Large capacity semispan balances exist that can make the use of gravity weights for their calibration simply not practical. NASA's MC400 semispan balance is a good example for that situation. The MC400 has a normal force capacity of 40,000 [lbs] and an axial force capacity of 8,000 [lbs]. Therefore, hydraulic actuators in combination with load cells need to be used to load the balance gages to capacity.

The MC400 was calibrated in 2012 in Triumph Aerospace's Large Load Rig (LLR). Figure 13a shows the installation of the MC400 in the LLR. The pitch axis of the balance is parallel to the gravity vector. Therefore, tare loads caused by the metric part of the balance, the rolling/yawing moment arm weight, and the weight of other fixtures cannot be neglected. Tare load estimates need to be included in the applied loads before a regression analysis of the calibration data can be performed. The estimated tare load during the calibration of the MC400 in the LLR was on the order of 1,900 [lbs] (approximately 400 [lbs] weight of the metric part of the balance plus 1,500 [lbs] weight of the moment arm and other calibration fixtures).

Figure 13b shows the normal force load chain that was used during the calibration of the MC400 in the LLR. The load chain has four major parts: hydraulic actuator, flexure, load cell, and leveling plate. The actuator applies the load. The flexure and the leveling plate are needed for the correct alignment of the load. The load cell is needed for the precise measurement of the load after its alignment.

Figure 13c shows the current rolling/yawing moment arm capability of the LLR's hardware. The lower moment arm limit is 40 inches. The upper moment arm limit is 60 inches. These two moment arm limits define the green sectors depicted in Fig. 6a and Fig. 6b. Ideally, the moment arm of the resultant normal force and axial force should be within the LLR's moment arm range whenever a semispan model is tested in a wind tunnel using the MC400 balance.

Figure 13d shows actuator 1 that is used to apply the normal force. It is a tension-only actuator as the LLR has a "floating" top frame. Therefore, the balance needs to be rotated by 180 degrees in order to change the sign of the normal force component.

Figure 13e shows actuator 2 that is used to apply the pitching moment. The actuator can apply both tension and compression loads. Consequently, no significant modifications of this load chain need to be made in order to change the sign of the pitching moment. Actuator 2 applies a tension or compression force that is parallel to the normal force that is generated by actuator 1 . Therefore, the total normal force is the sum of the forces applied by actuator 1 and actuator 2 (see also Fig. 13f).

A third actuator, i.e., actuator 3, is used to apply the axial force in the LLR. By design, this actuator is perpendicular to both the pitch axis of the balance and the direction of the normal force. Both actuator 1 and actuator 3 are attached to the LLR's rolling/yawing moment arm so that combinations of normal force and axial force can be applied. Figure 13g shows the installation of actuator 3 in the LLR.

Both NASA Langley's semispan balance calibration load rig (Fig. 12) and Triumph Aerospace's LLR (Figs. 13a to 13g) have the disadvantage that the balance sees large tare loads even if no calibration load is applied. The tare loads have to be numerically determined by using a tare load iteration process (see Ref. [1]), or, alternatively, by physically weighing the individual pieces of the calibration hardware. The latter approach, unfortunately, cannot capture loads caused by the metric part of the balance. They would have to be determined by combining a volume estimate of the metric part of the balance with its material density. Therefore, the author prefers the use of a tare load iteration process as loads caused by the metric part of the balance and by all fixtures are included in the numerical tare load estimates.

A 5-component semispan balance is one of only a few balance types that can be orientated relative to gravity such that (i) tare loads become zero by design and (ii) gage outputs directly correspond to the natural zeros whenever the applied calibration loads are zero. Therefore, it is theoretically possible to design a calibration rig for a 5-component semispan balance that will never experience a tare load. This hypothetical rig would have the advantage that (i) numerical errors associated with the tare load assessment can completely be avoided and (ii) the gage outputs at the beginning and end of a load series can more easily be monitored during the calibration as they always have to be close to the natural zeros.

Figures 14a and 14b depict a hypothetical "tare-load-free" calibration rig concept that the author developed for the calibration of a 5-component semispan balance. The proposed rig is assumed to use four hydraulic actuators for the application of calibration loads. The balance is oriented in the rig such that its pitch axis is parallel to the gravitational acceleration. Then, assuming that the center of gravity of the calibration hardware is on the pitch axis of the balance, tare loads caused by the metric part of

American Institute of Aeronautics and Astronautics 
the balance and the calibration hardware are zero because the tare loads act in the direction of the pitch axis. Consequently, the balance gages will read values that are very close to their natural zeros whenever no calibration load is applied. In addition, moment arm hardware with octogonal cross-section should be used so that actuators chosen for the application of the normal force and axial force can easily be placed right next to the actuator pair that applies the pitching moment. Figure 14a shows the general layout of the "tare-load-free" calibration rig. The pitching moment arm is omitted in Fig. 14a for clarity. Figure 14b shows the installation of the pitching moment arm of the proposed calibration rig. The moment arm has to be symmetric so that the tare loads on the 5-component semispan balance remain zero. In addition, the pitching moment arms are attached to the octogonal column such that the connection of the pitching moment arm pair does not interfer with attachment points of both the normal and axial force load chain.

\section{Full Characterization}

In theory, a full characterization of the behavior of a balance is possible if calibration data is available for analysis that was obtained by applying all possible combinations of the independent calibration variables (also described in the literature as "exhausting all combinations of the independent calibration variables"). This approach has two major advantages: (i) important characteristics of the balance are not accidently overlooked if a new balance design is characterized for the first time and (ii) a large amount of experimental information about complex balance gage interactions is contained in the calibration data.

Often, however, it is not possible to collect data needed for a full characterization of a balance as (i) the number of required calibration points can be very large, (ii) the balance calibration rig may be unable to apply certain load combinations, and (iii) the cost for a full characterization can be high. Nevertheless, it is useful to understand some basic requirements of a full characterization of a 5-component semispan balance because this type of balance simultaneously experiences all five load components for the vast majority of wind tunnel test conditions. This unique feature of a 5-component semispan balance is caused by the fact that neither the line defined by the resultant normal force on the semispan model nor the line defined by the resultant axial force on the semispan model will usually intersect the pitch axis of the balance.

A calibration data set for a full characterization of a 5-component semispan balance can be obtained after first choosing the levels of the calibration variables. It is assumed that the calibration variable set consists of three load components (normal force, axial force, pitching moment) and two geometric distances (rolling moment arm, yawing moment arm). The balance calibration rig allows for the independent application of the normal force, axial force, and pitching moment at the following five levels: $\pm 100 \%, \pm 50 \%, 0 \%$ (the five levels are expressed as a percentage of the load capacity and assumed to provide a sufficiently accurate description of the balance behavior). In addition, the chosen calibration rig supports the independent selection of three geometric distances for both the rolling and yawing moment arm $\left(0<D_{1}<D_{2}<D_{3}\right.$ and $\left.0<d_{1}<d_{2}<d_{3}\right)$. Consequently, after applying all possible combinations of the five independent calibration variables, a total of 1125 data points $(5 \times 5 \times 5 \times 3 \times 3)$ need to be recorded to obtain the data set for the full characterization of the 5-component semispan balance. Furthermore, assuming that the calibration is performed by changing only the normal force during a load series while keeping all other independent calibration variables constant, a total of 225 load series are needed to apply all 1125 data points.

Discussions of the author with Chris Lynn and Sean Commo of NASA Langley Research Center made the author realize that it may be beneficial to include calibration points at the balance moment center of the semispan balance in the calibration data set. These points help define the final regression model of the calibration data at a physical limit of the balance. Therefore, a second alternate approach was developed that may also be used to collect experimental data for a full characterization of a 5-component semispan balance. The alternate approach requires fewer calibration points than the approach that was discussed the previous paragraph. The alternate approach simply splits the combinations needed for a full characterization into two parts, i.e., Part 1 and Part 2, and merges the data sets afterwards.

Part 1 of the alternate approach is defined similar to the original approach that is described above. Again, it is assumed that the normal force, axial force, and pitching moment can independently be applied at five levels: $\pm 100 \%, \pm 50 \%, 0 \%$. In addition, the chosen calibration rig supports the independent selection of two geometric distances for both the rolling and yawing moment arm $\left(0<D_{1}<D_{2}\right.$ and $\left.0<d_{1}<d_{2}\right)$. Consequently, assuming that all possible combinations of the five independent calibration variables are

American Institute of Aeronautics and Astronautics 
applied, a total of 500 data points $(5 \times 5 \times 5 \times 2 \times 2)$ need to be recorded for the completion of Part 1 .

Part 2 of the alternate approach is obtained assuming that the calibration rig allows for an independent application of the normal force, axial force, and pitching moment at the balance moment center of the balance. In that case, the rolling moment arm, yawing moment arm, and the related two moments are zero by design. In other words, Part 2 places data points on the axes $D=0$ and $d=0$ that are shown in Figs. 5a and 5b. These data points help "anchor" regression models of the calibration data to conditons seen at the balance moment center even though the resultant normal and axial forces on the balance will never be at the balance moment center during a wind tunnel test. Then, assuming again that the normal force, axial force, and pitching moment are applied at five levels each $( \pm 100 \%, \pm 50 \%, 0 \%)$, the total number of calibration points needed for the completion of Part 2 is $125(5 \times 5 \times 5)$. Finally, the calibration data sets of Part 1 and Part 2 are merged into a single calibration data set that has a total of 625 data points.

\section{Summary and Conclusions}

The selection of independent variables for the calibration of a 5-component semispan balance and a 3-component canard balance was discussed in great detail. In addition, the combined load diagrams of a semispan balance were introduced in order to illustrate the connection between calibration load schedule design, wind tunnel model geometry, and test section size. Then, the determination of the natural zeros of a semispan balance and the application of calibration loads in three different semispan balance calibration rig designs were reviewed. Finally, examples of requirements for a balance calibration data set were discussed that may be used for a full characterization of a 5-component semispan balance.

It is concluded that the calibration load schedule design for a semispan balance should focus equally on the rolling/yawing moment capacities of the balance and the rolling/yawing moment arm ranges of the calibration rig. The load schedule design has to guarantee, of cause, that the rolling/yawing moment capacities of the semispan balance are not exceeded during its calibration so that balance gages and flexures are not damaged. However, it is also important to ensure that the rolling/yawing moment arm ranges of the calibration rig are selected such that the expected moment arms of the resultant normal and axial forces on a wind tunnel model are within the moment arm ranges of the calibration rig.

Finally, it must not be overlooked that a "real-world" semispan model always experiences a side force during a wind tunnel test. This side force is not necessarily located on the pitch axis of the balance. Therefore, the side force has an "indirect" influence on the electrical outputs of both the rolling and yawing moment gages of a 5-component semispan balance even though the side force is not an independent calibration variable for this type of balance.

\section{Acknowledgements}

The author would like to thank Jon Bader and Bob Gisler of NASA Ames Research Center and Chris Lynn of NASA Langley Research Center for reviewing the final manuscript of the paper. Thanks also go to Dennis Booth of Triumph Aerospace for giving permission to use images of the Large Load Rig. The work reported in this paper was supported by the Wind Tunnel Division at NASA Ames Research Center under contract NNA09DB39C.

\section{References}

${ }^{1}$ AIAA/GTTC Internal Balance Technology Working Group, "Recommended Practice, Calibration and Use of Internal Strain-Gage Balances with Application to Wind Tunnel Testing," AIAA R-091-2003, American Institute of Aeronautics and Astronautics, Reston, Virginia, 2003.

${ }^{2}$ Ulbrich, N., "Combined Load Diagram for a Wind Tunnel Strain-Gage Balance," AIAA 2010-4203, paper presented at the 27th AIAA Aerodynamic Measurement Technology and Ground Testing Conference, Chicago, Illinois, June/July 2010.

${ }^{3}$ Ulbrich, N., and Gisler, B., "A Baseline Load Schedule for the Manual Calibration of a Force Balance," paper to be presented at the 51st AIAA Aerospace Sciences Meeting and Exhibit, Grapevine (Dallas/Ft. Worth region), Texas, January 2013. 


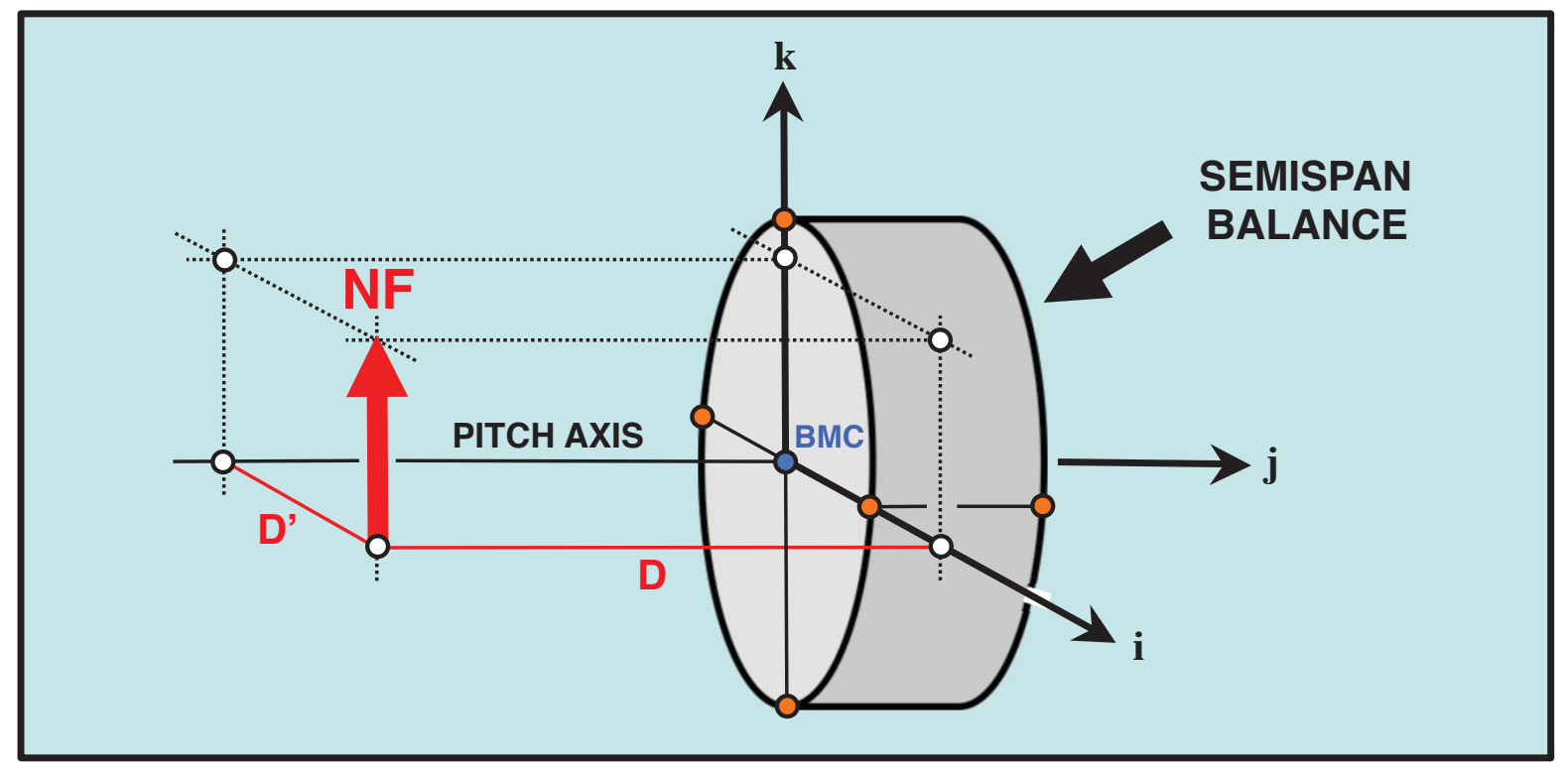

Fig. 1a Location of the resultant normal force relative to the balance moment center for a left wing semispan wind tunnel model (BMC $\equiv$ balance moment center).

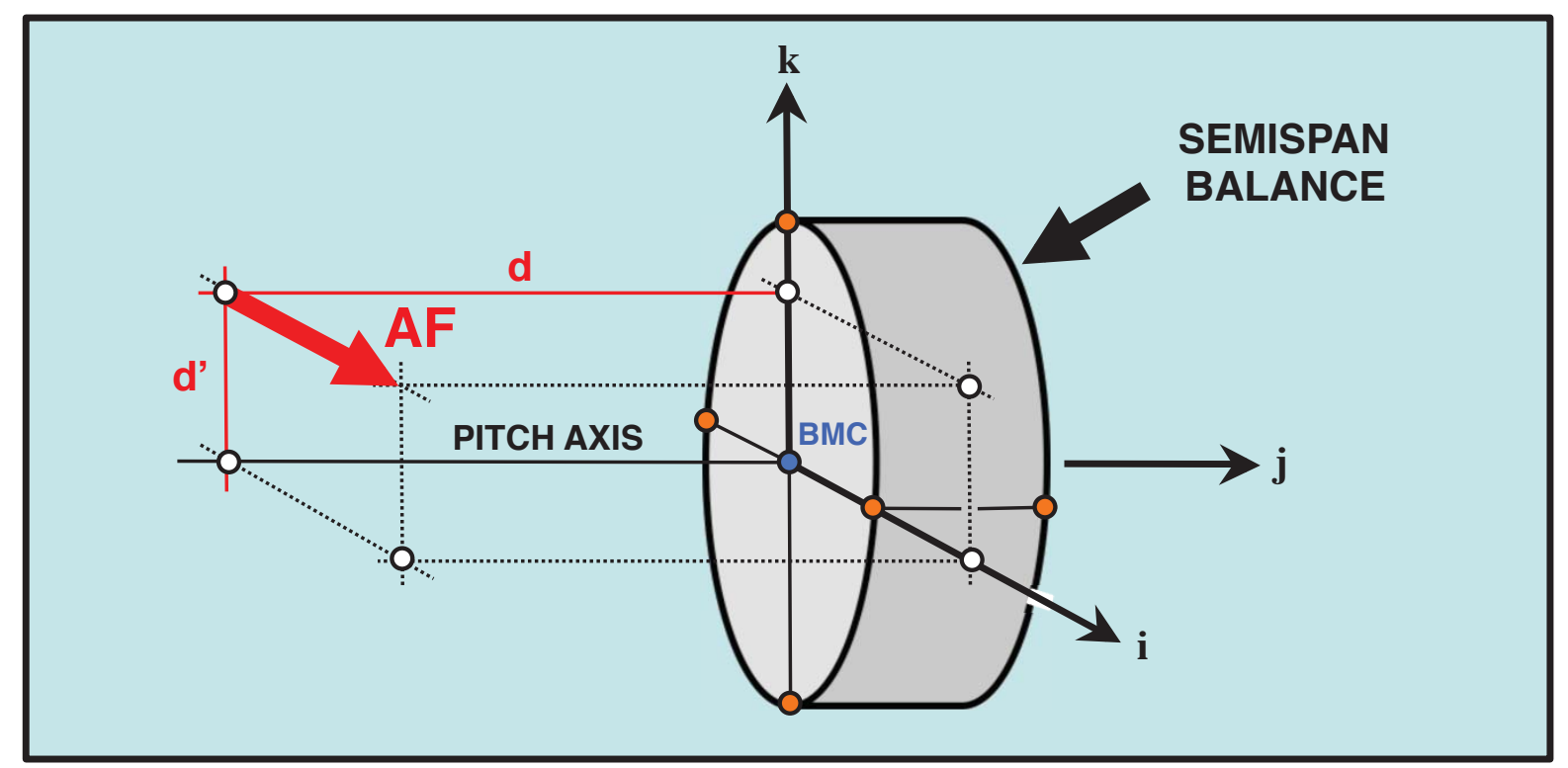

Fig. 1b Location of the resultant axial force relative to the balance moment center for a left wing semispan wind tunnel model (BMC $\equiv$ balance moment center). 

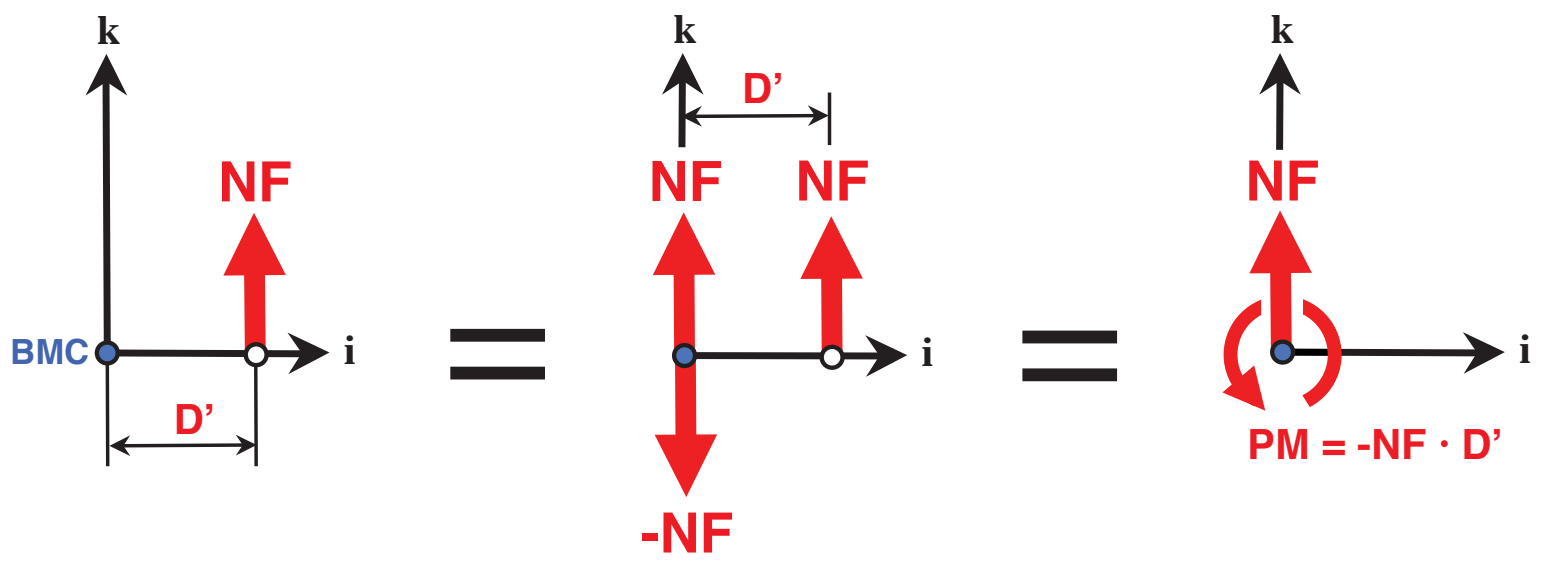

Fig. 2 Shift of the normal force to the pitch axis of the semispan balance.
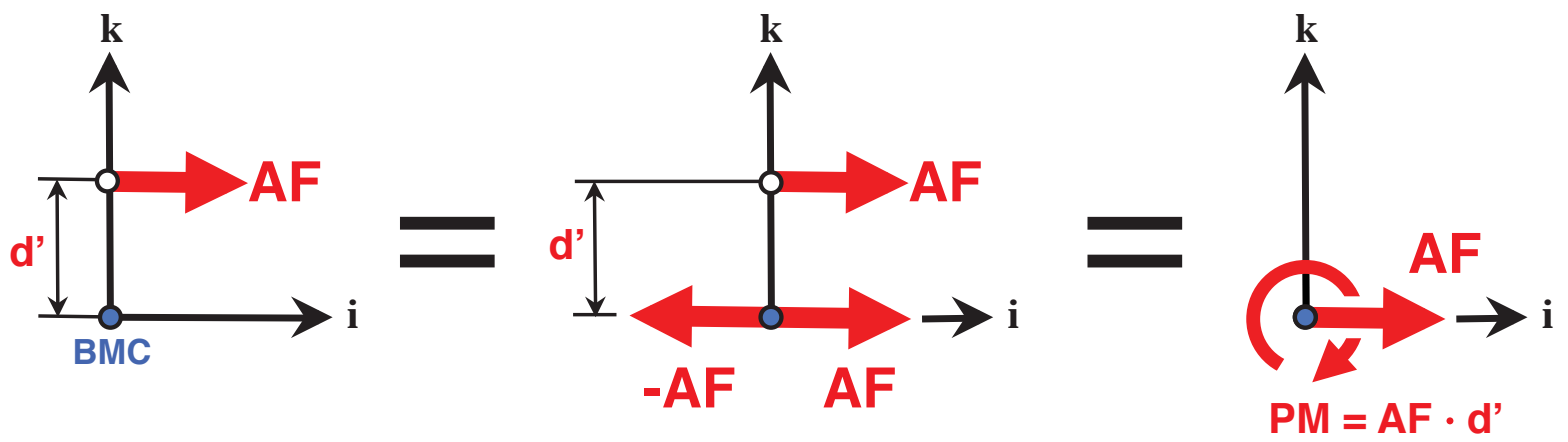

Fig. 3 Shift of the axial force to the pitch axis of the semispan balance. 


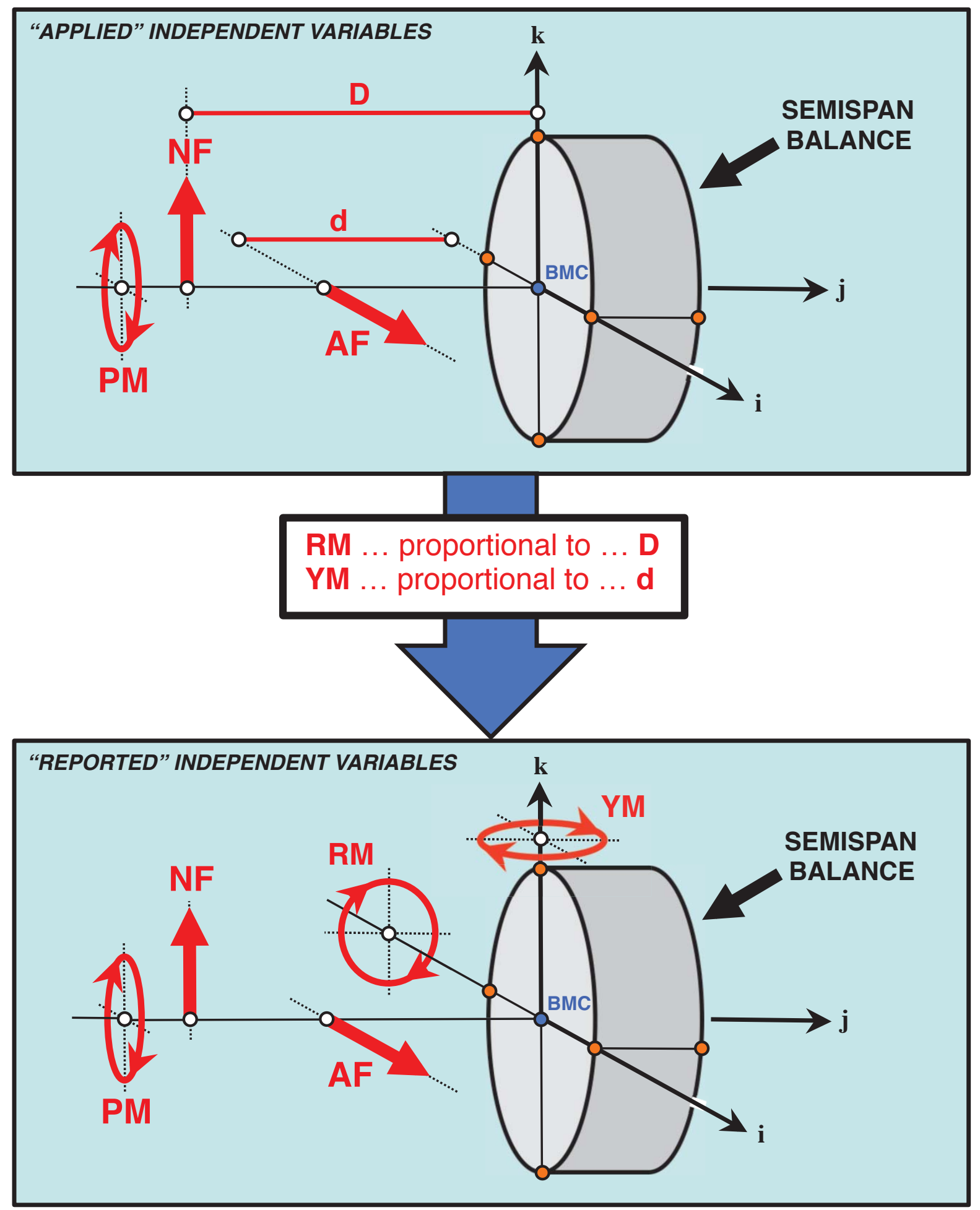

(sign convention of forces \& moments is taken from AIAA R-091-2003, p.3)

Fig. 4a Calibration variable set options for a 5-component semispan balance. 

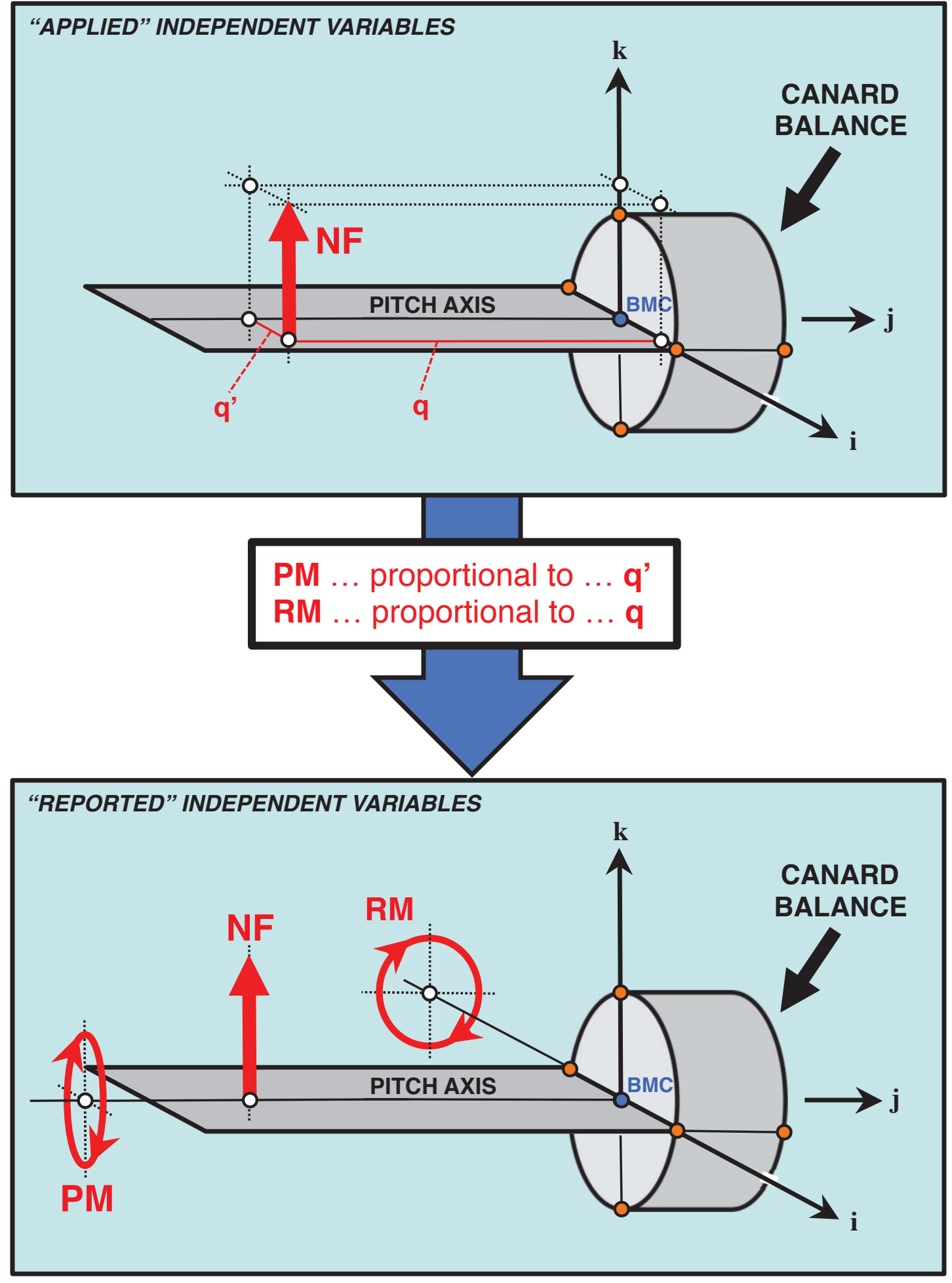

(sign convention of forces \& moments is taken from AIAA R-091-2003, p.3)

Fig. 4b Calibration variable set options for a 3-component canard balance. 


\section{LEFT WING $\Rightarrow \mathrm{RM}=\mathrm{NF} \cdot \mathrm{D}$}

BLUE DOT = BALANCE MOMENT CENTER (BMC)

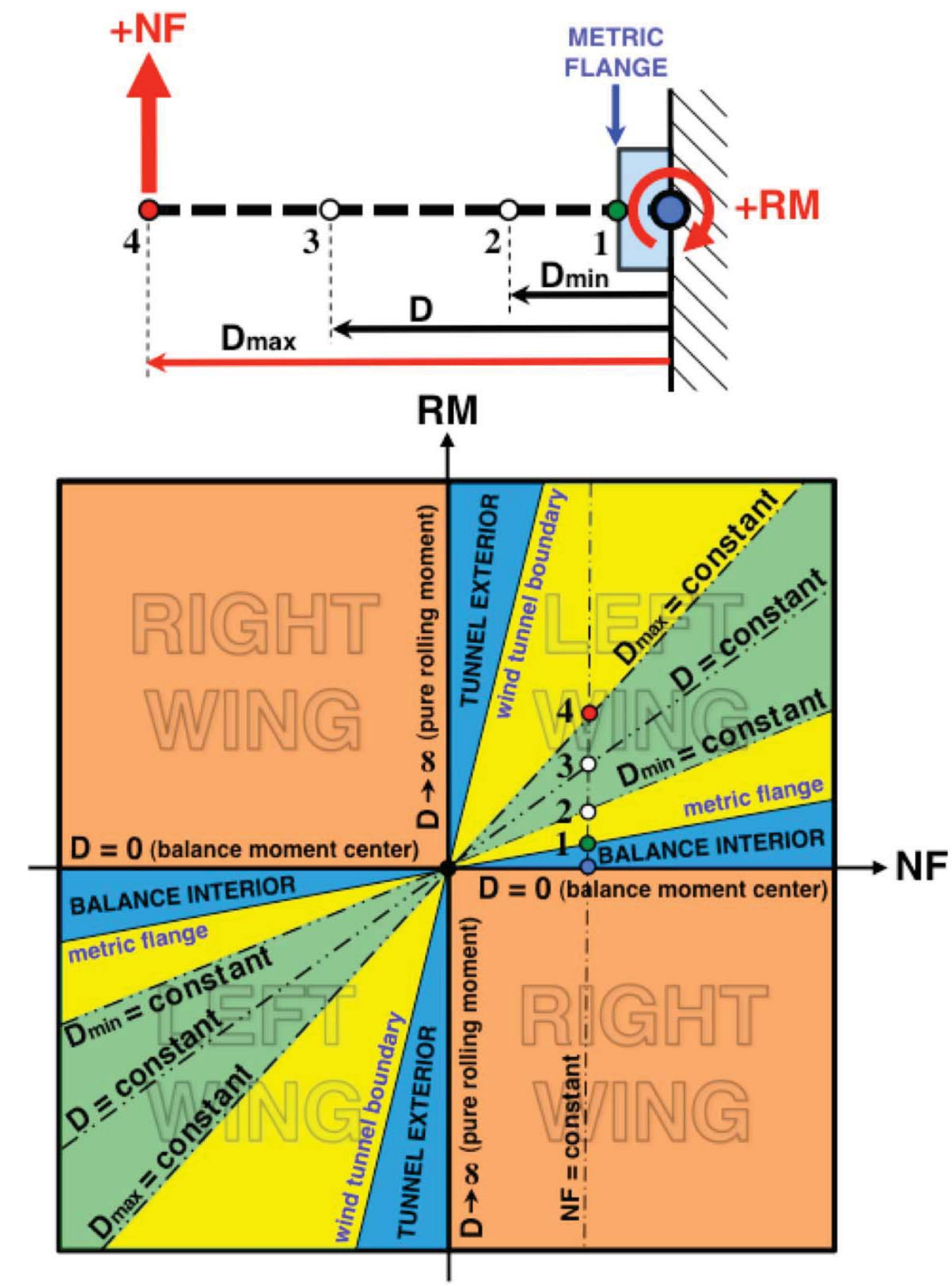

(sign convention of forces \& moments is taken from AIAA R-091-2003, p.3)

Fig. 5a Combined load diagram for the normal force and the rolling moment. 


\section{LEFT WING $\Rightarrow \mathrm{YM}=(-\mathrm{AF}) \cdot \mathrm{d}$}

\section{BLUE DOT = BALANCE MOMENT CENTER (BMC)}

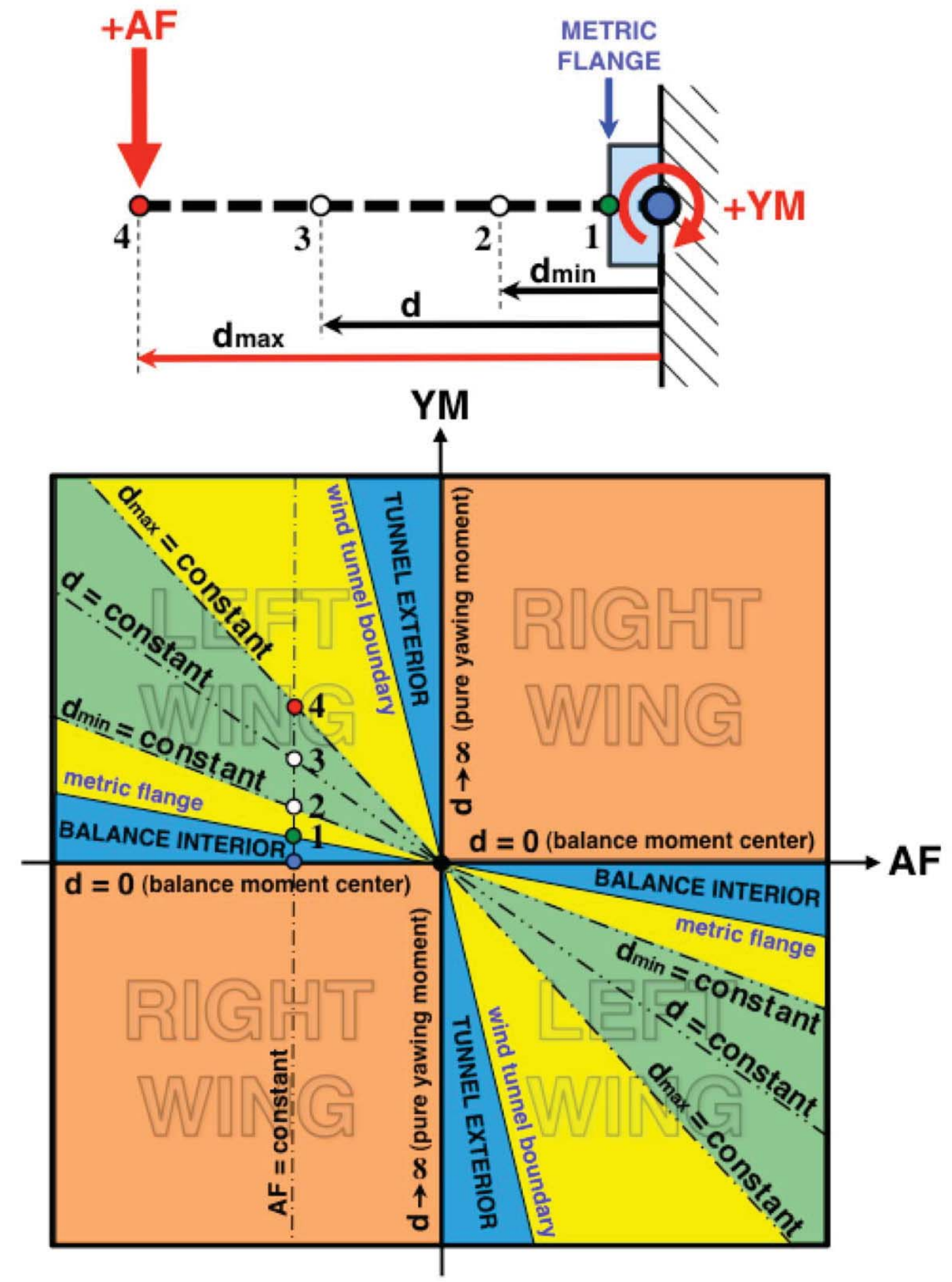

(sign convention of forces \& moments is taken from AIAA R-091-2003, p.3)

Fig. 5b Combined load diagram for the axial force and the yawing moment. 

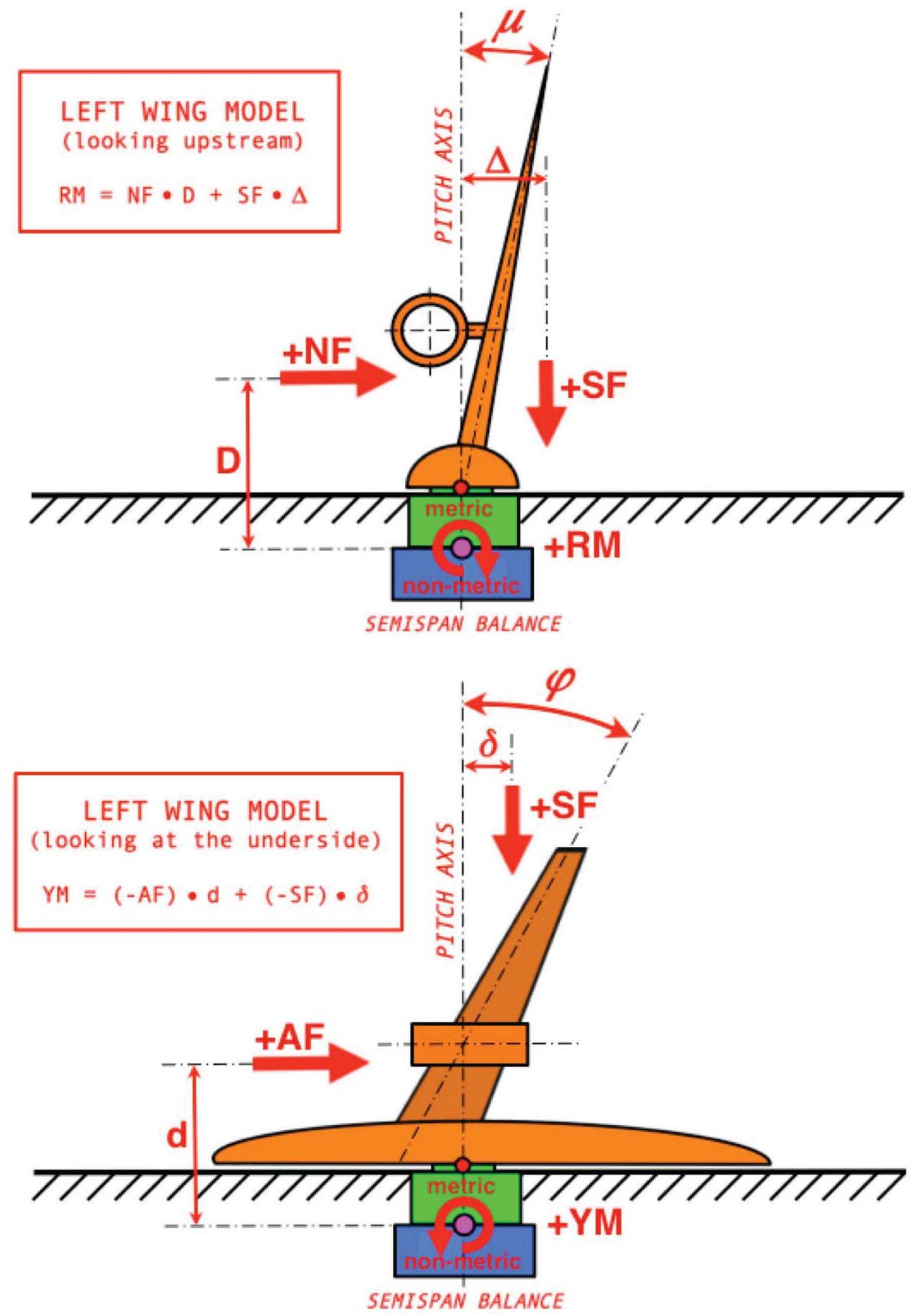

(sign convention of forces \& moments is taken from AIAA R-091-2003, p.3)

Fig. 5c Influence of the side force on the rolling/yawing moment measurements during a wind tunnel test. 


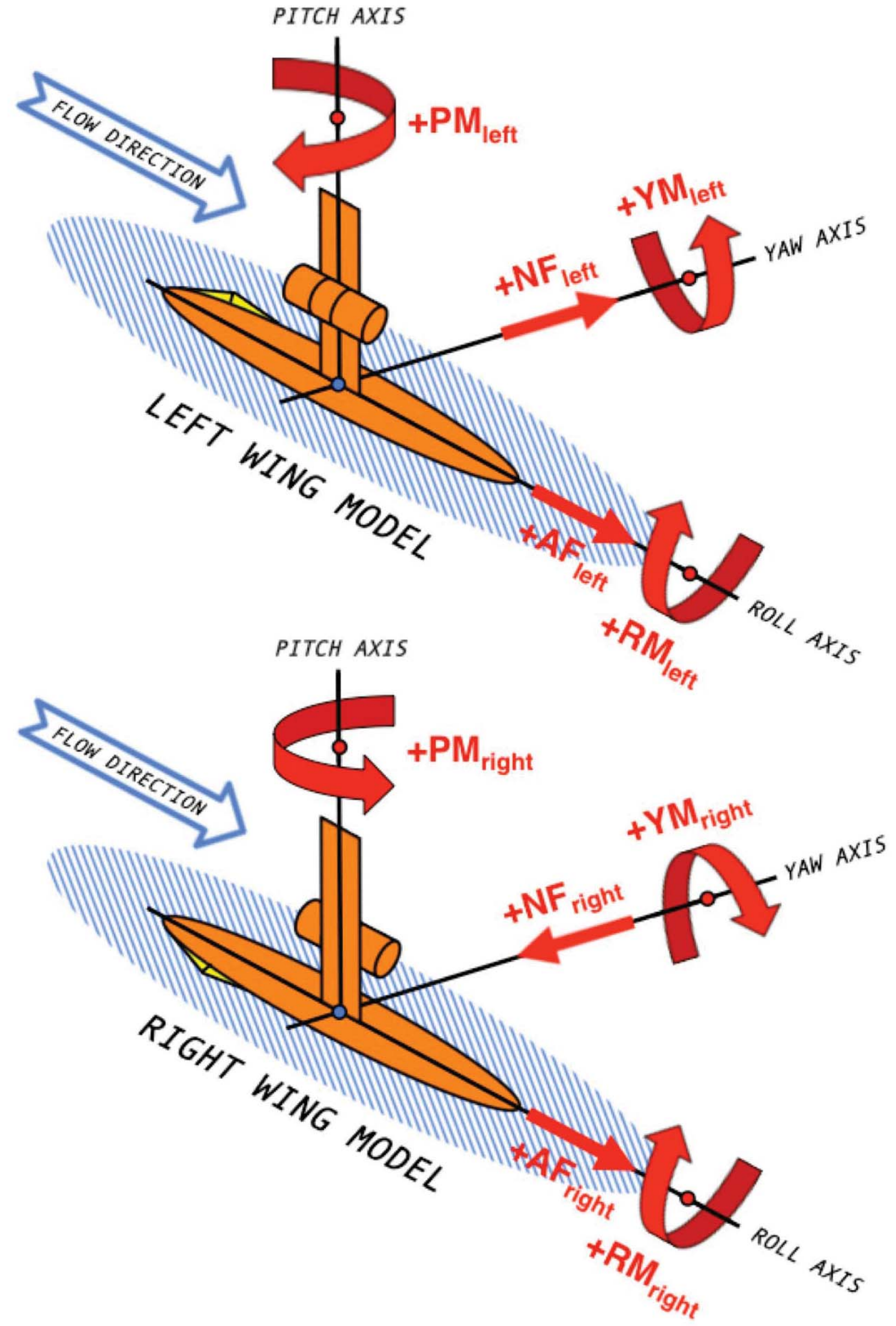

Fig. 6 Load sign convention for left and right wing semispan models in the balance axis system. 
("green" color identifies metric end of the semispan balance)

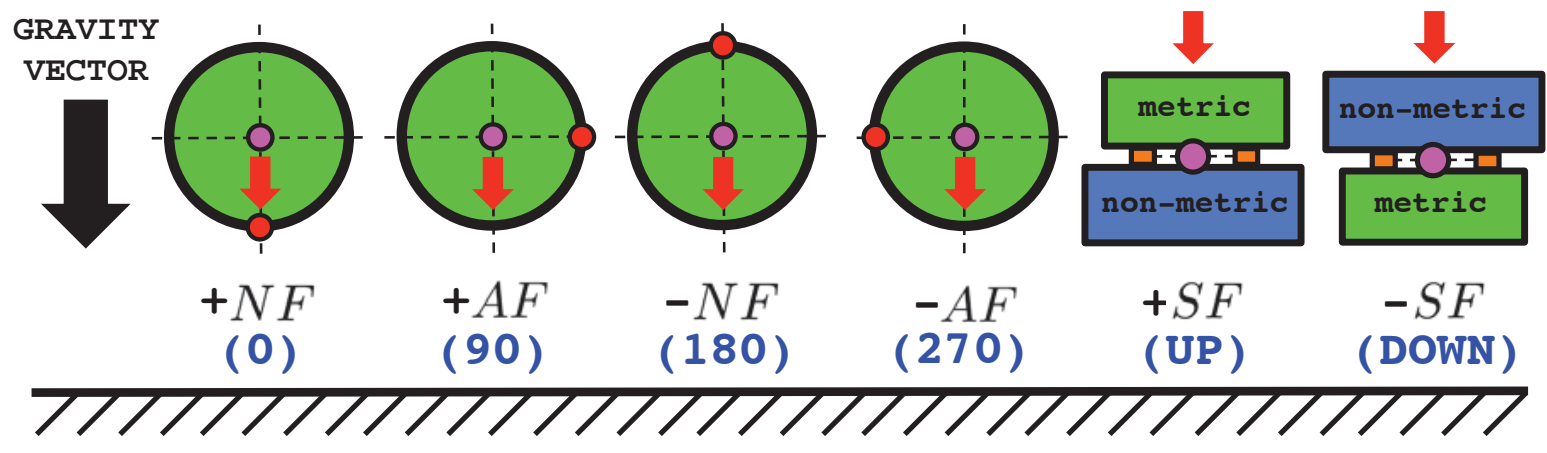

Fig. 7 Definition of semispan balance orientations relative to the direction of the gravitational acceleration.

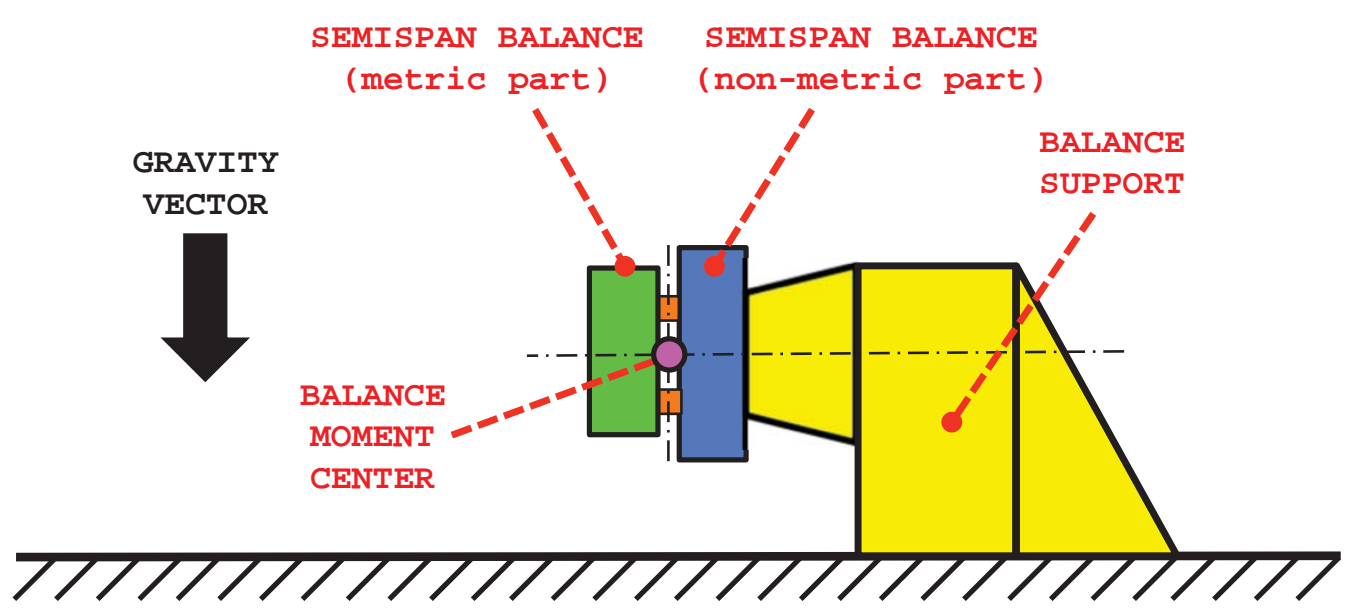

Fig. 8a Method I: Setup of a semispan balance for the determination of natural zeros.

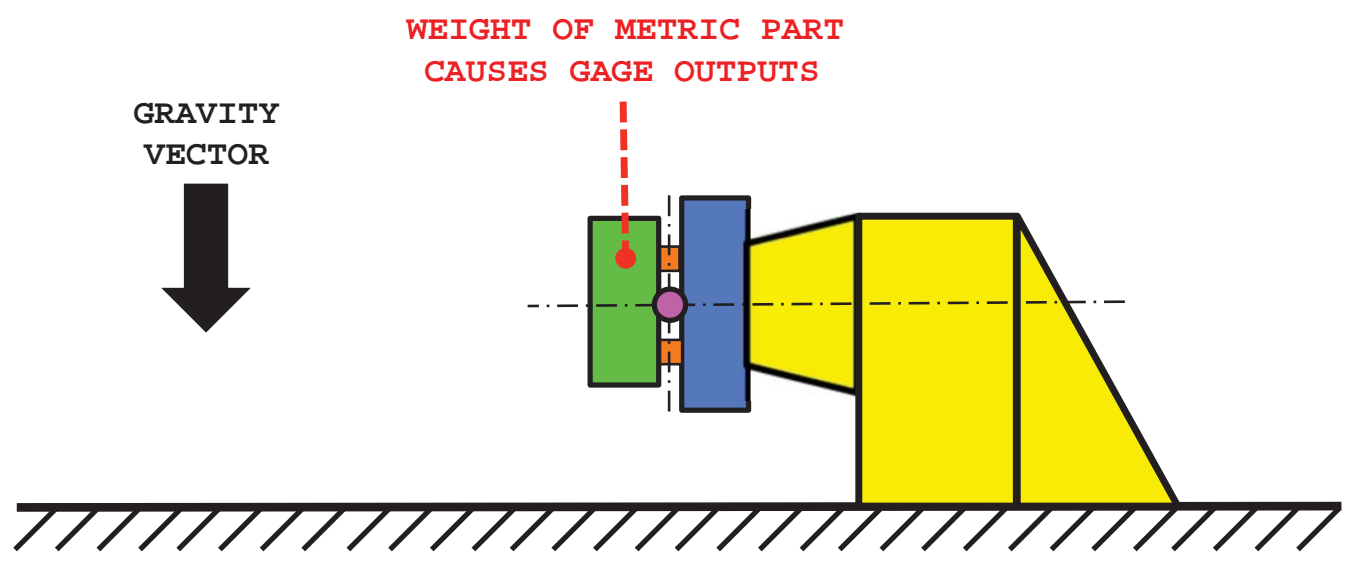

Fig. 8b Method I: Balance load experienced during the recording of natural zero points. 


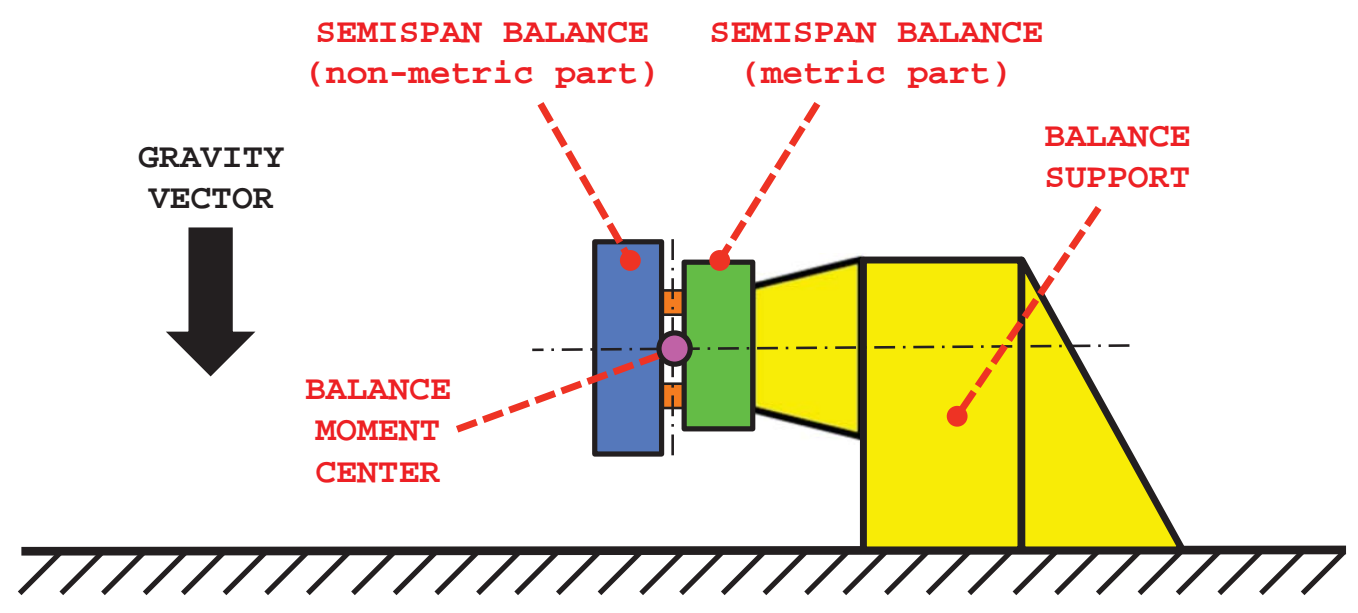

Fig. 9a Method II: Setup of a semispan balance for the determination of natural zeros.

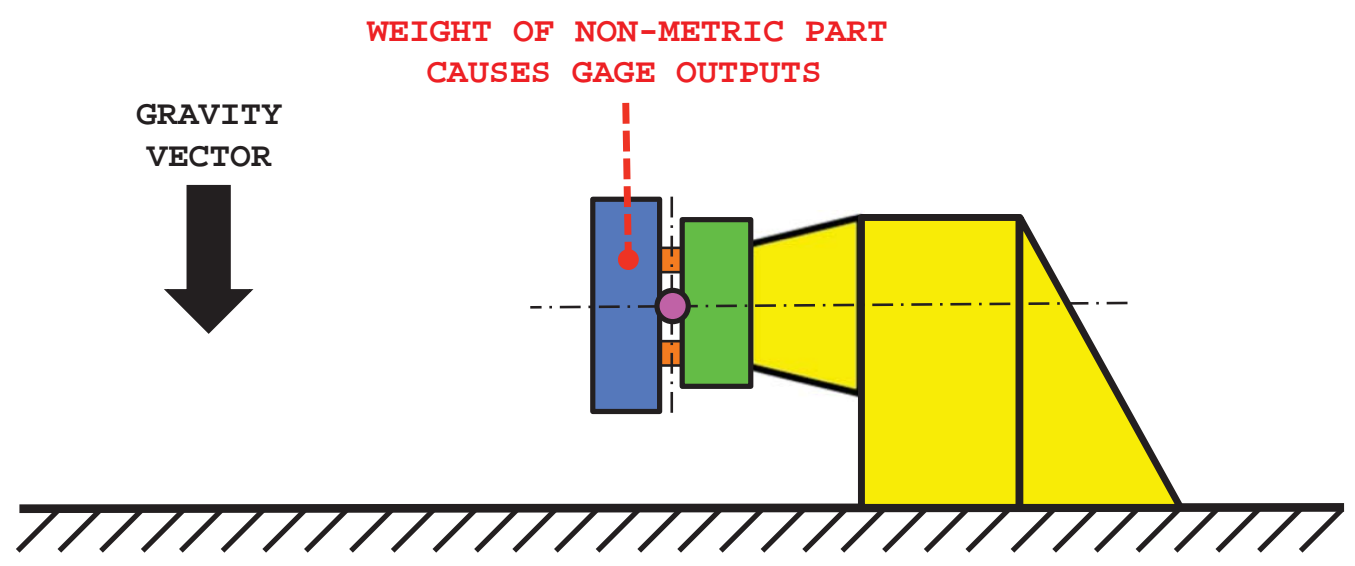

Fig. 9b Method II: Balance load experienced during the recording of natural zero points. 


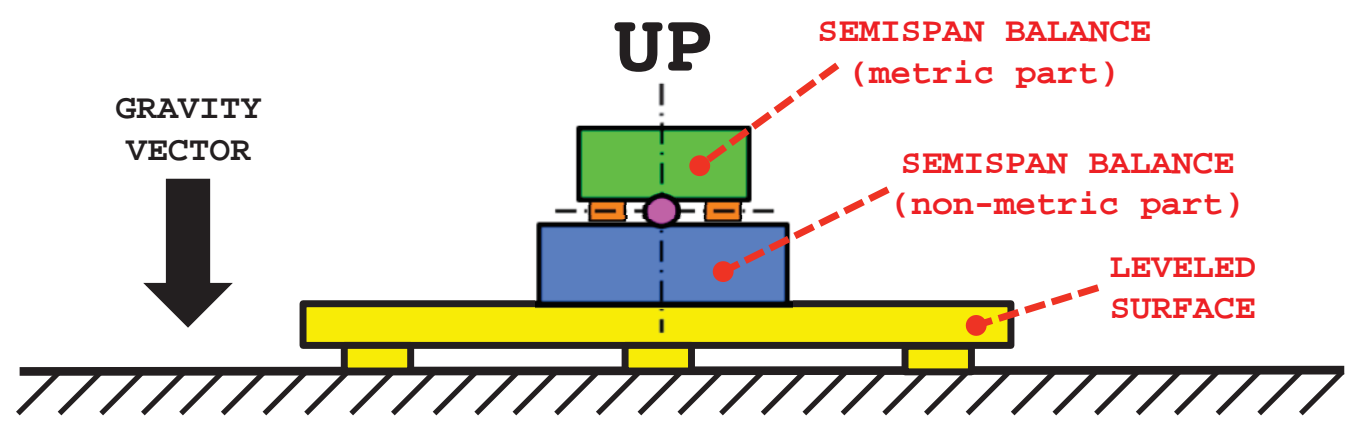

Fig. 10 Method III: Setup of a semispan balance for the determination of natural zeros.

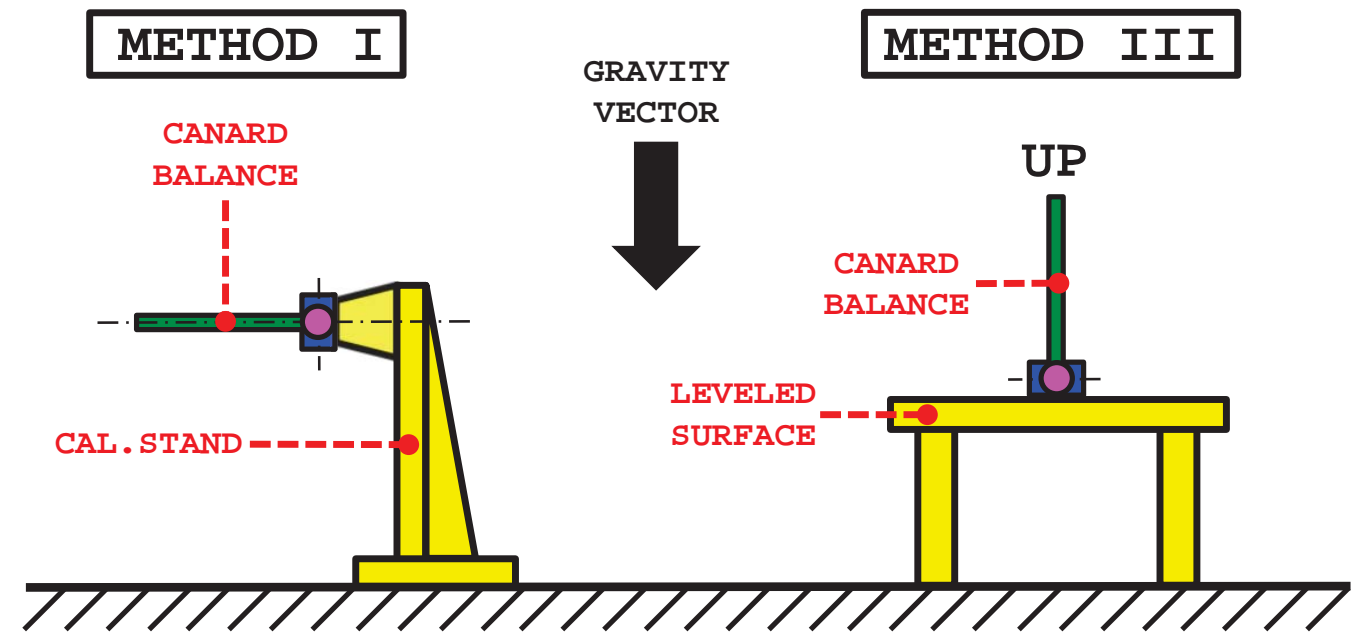

Fig. 11 Method I \& Method III: Setup of a canard balance for the determination of the natural zeros. 


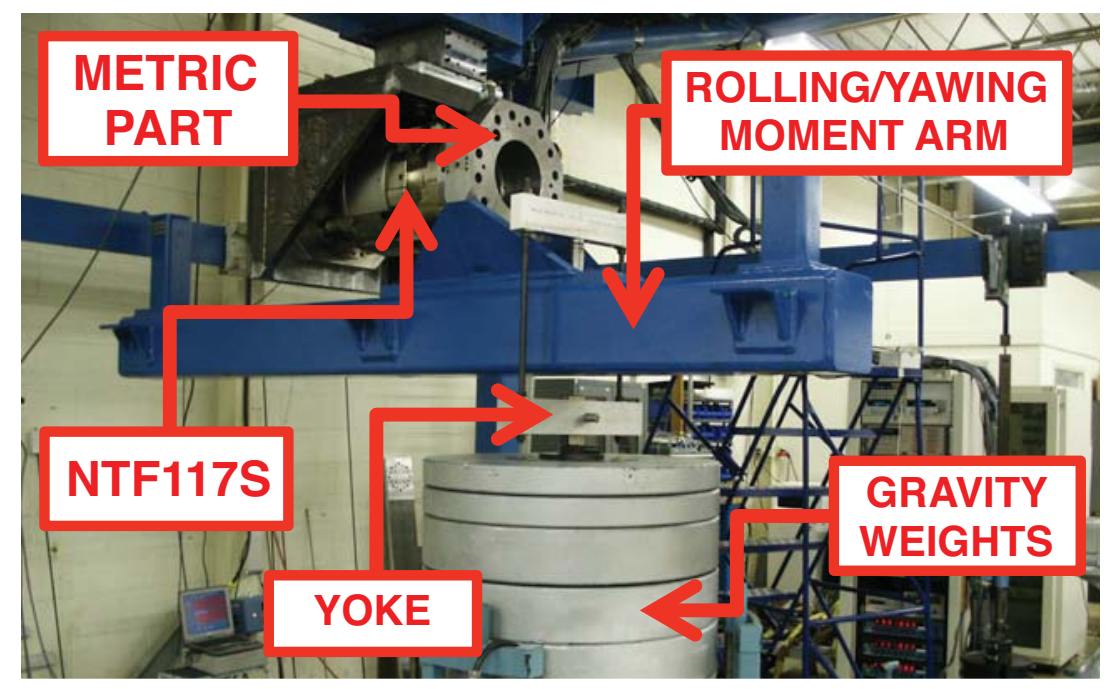

Fig. 12 NASA Langley's semispan balance calibration rig. (Image courtesy of NASA.)

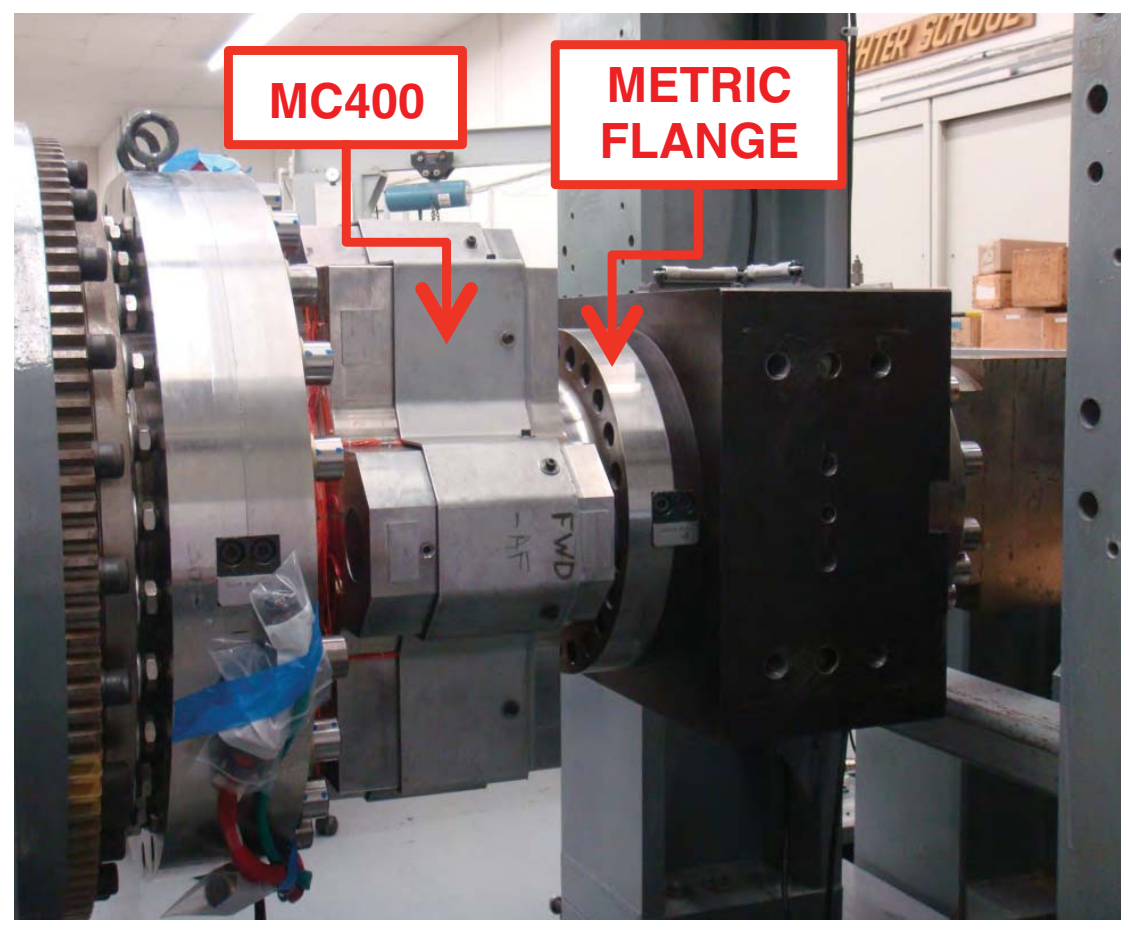

Fig. 13a MC400 balance in Triumph's Large Load Rig. (Image courtesy of Triumph Aerospace.) 


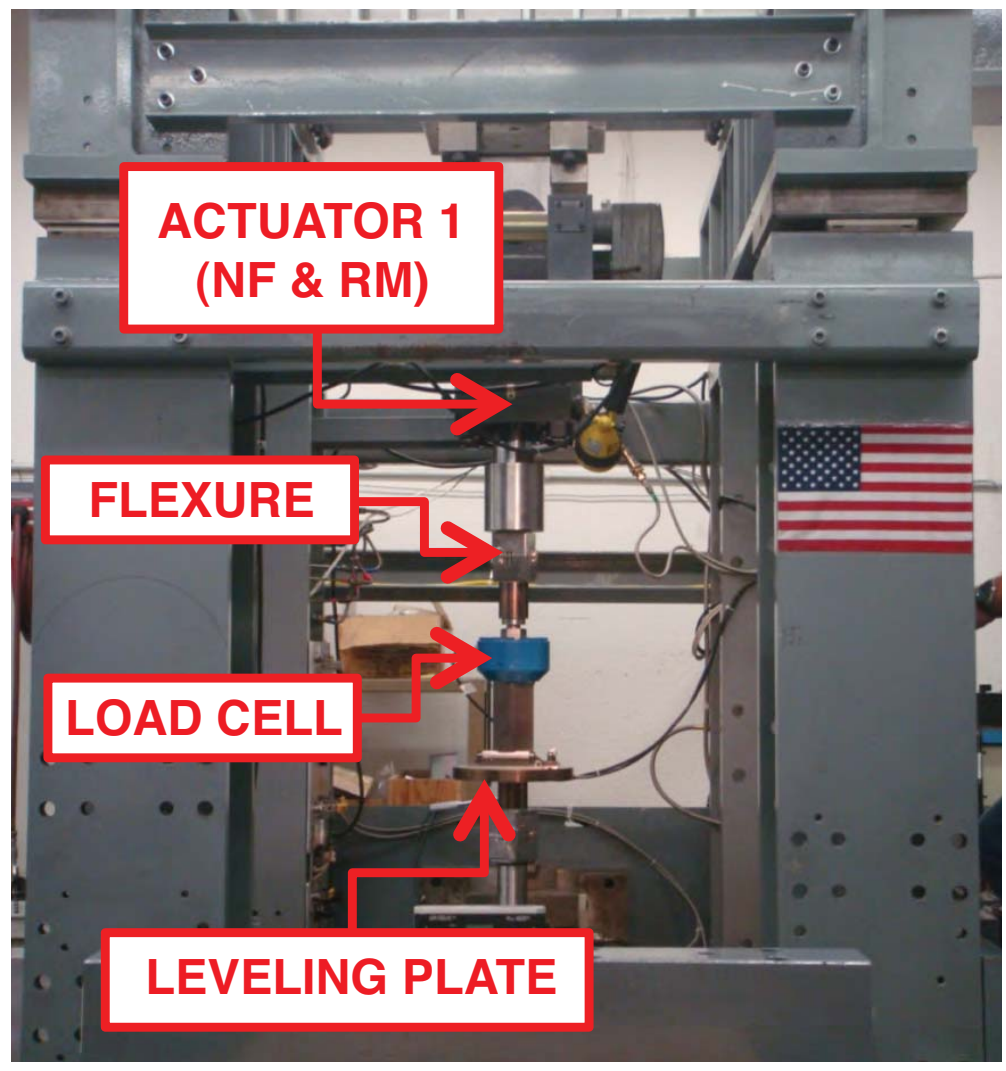

Fig. 13b Normal force load chain of the Large Load Rig. (Image courtesy of Triumph Aerospace.)

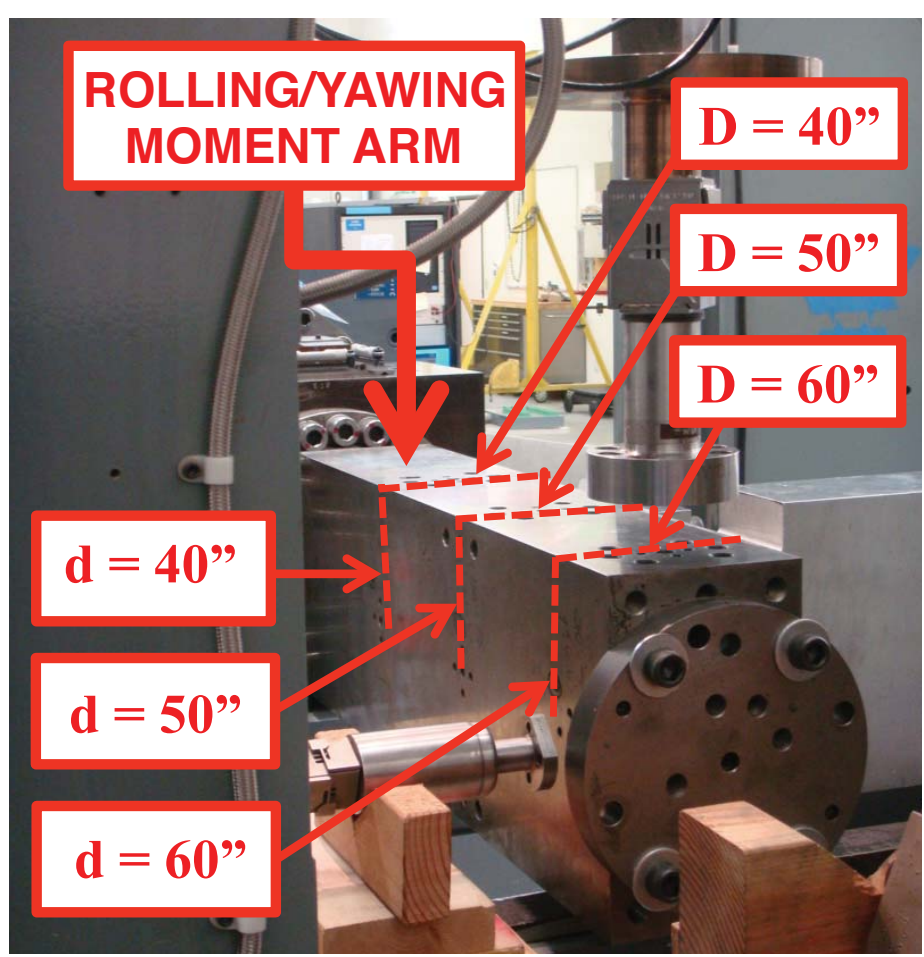

Fig. 13c Rolling/yawing moment arm options of the Large Load Rig. (Image courtesy of Triumph Aerospace.) 


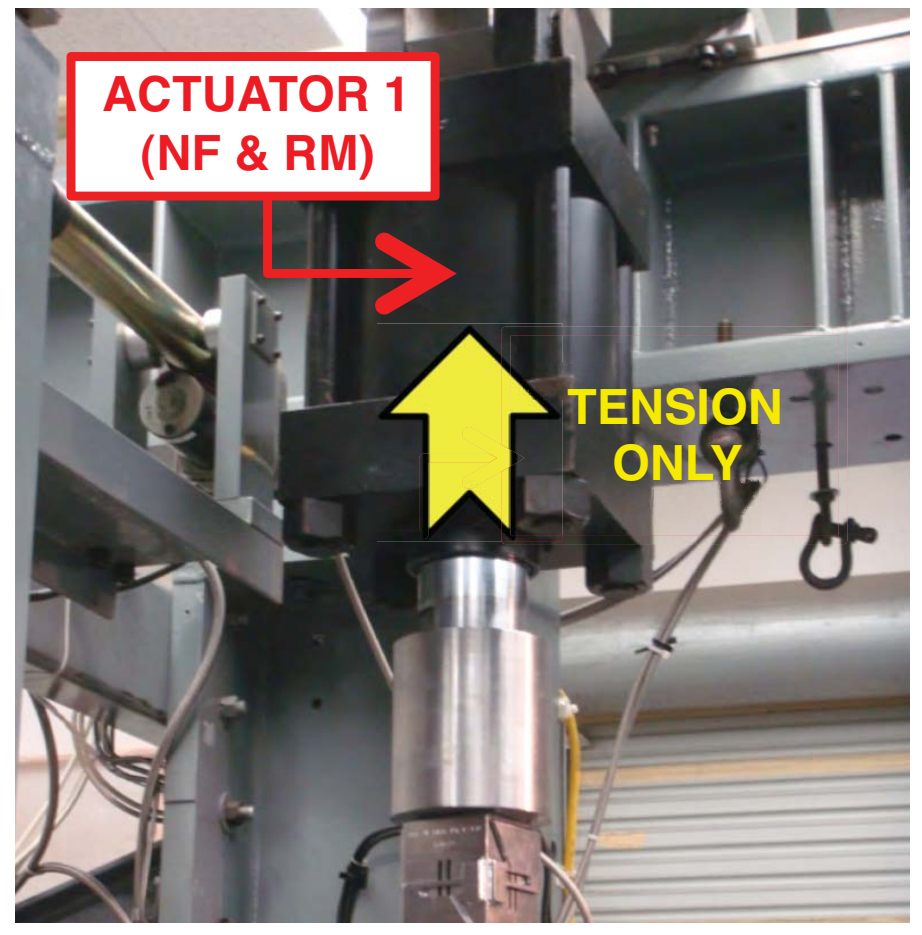

Fig. 13d Installation of hydraulic actuator 1. (Image courtesy of Triumph Aerospace.)

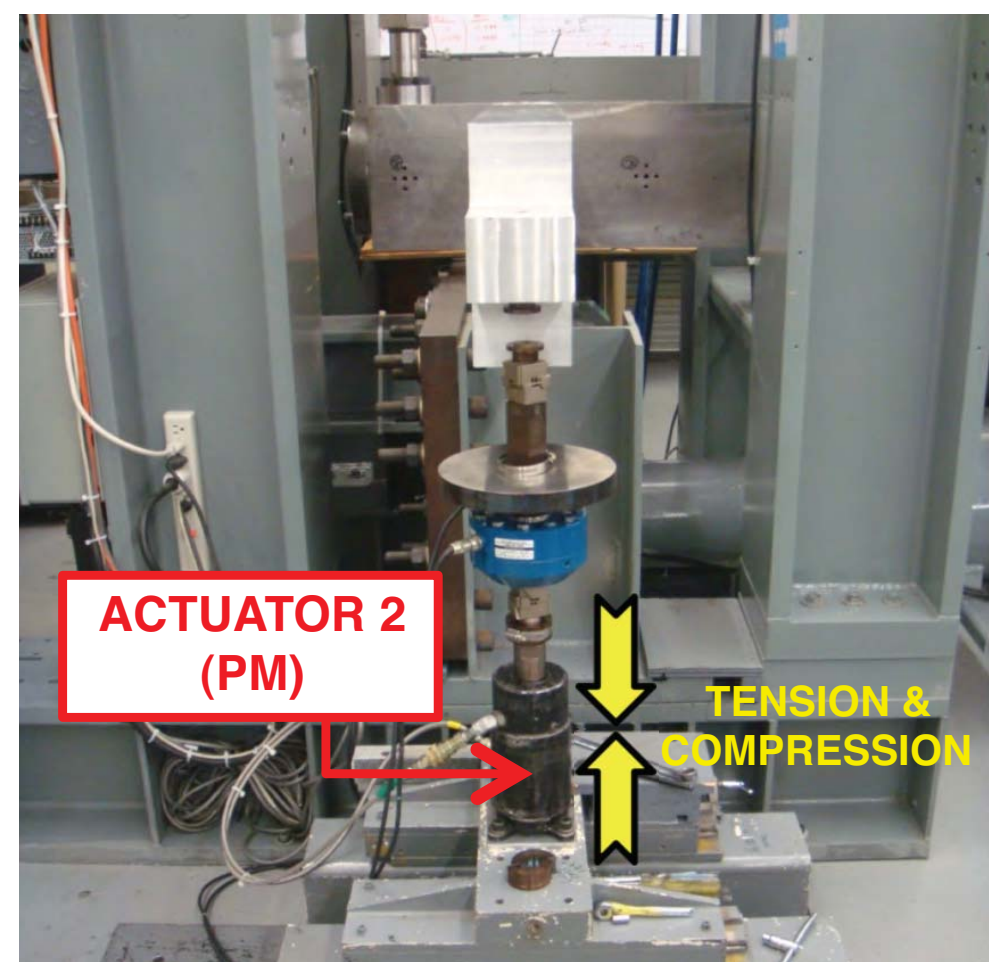

Fig. 13e Installation of hydraulic actuator 2. (Image courtesy of Triumph Aerospace.) 


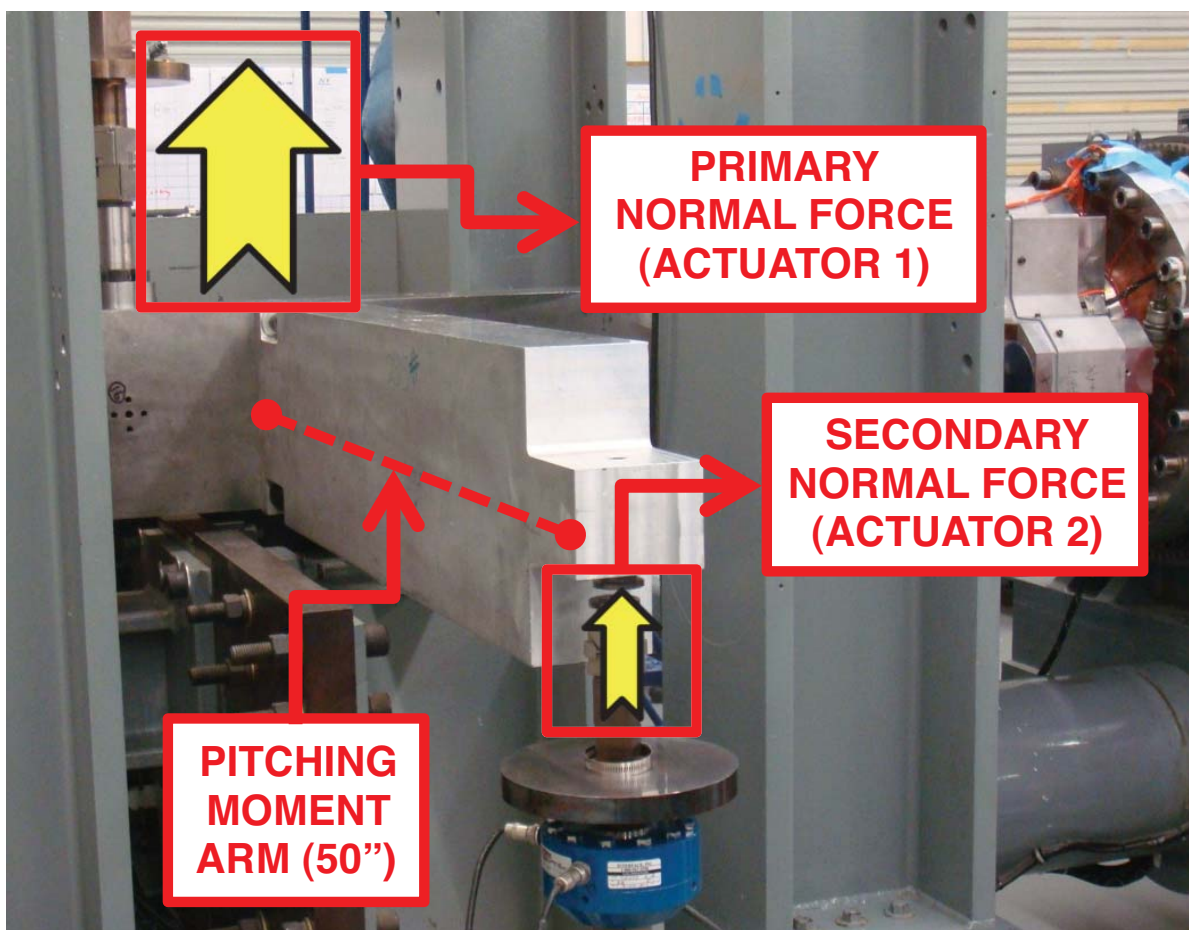

Fig. 13f Superposition of normal force components. (Image courtesy of Triumph Aerospace.)

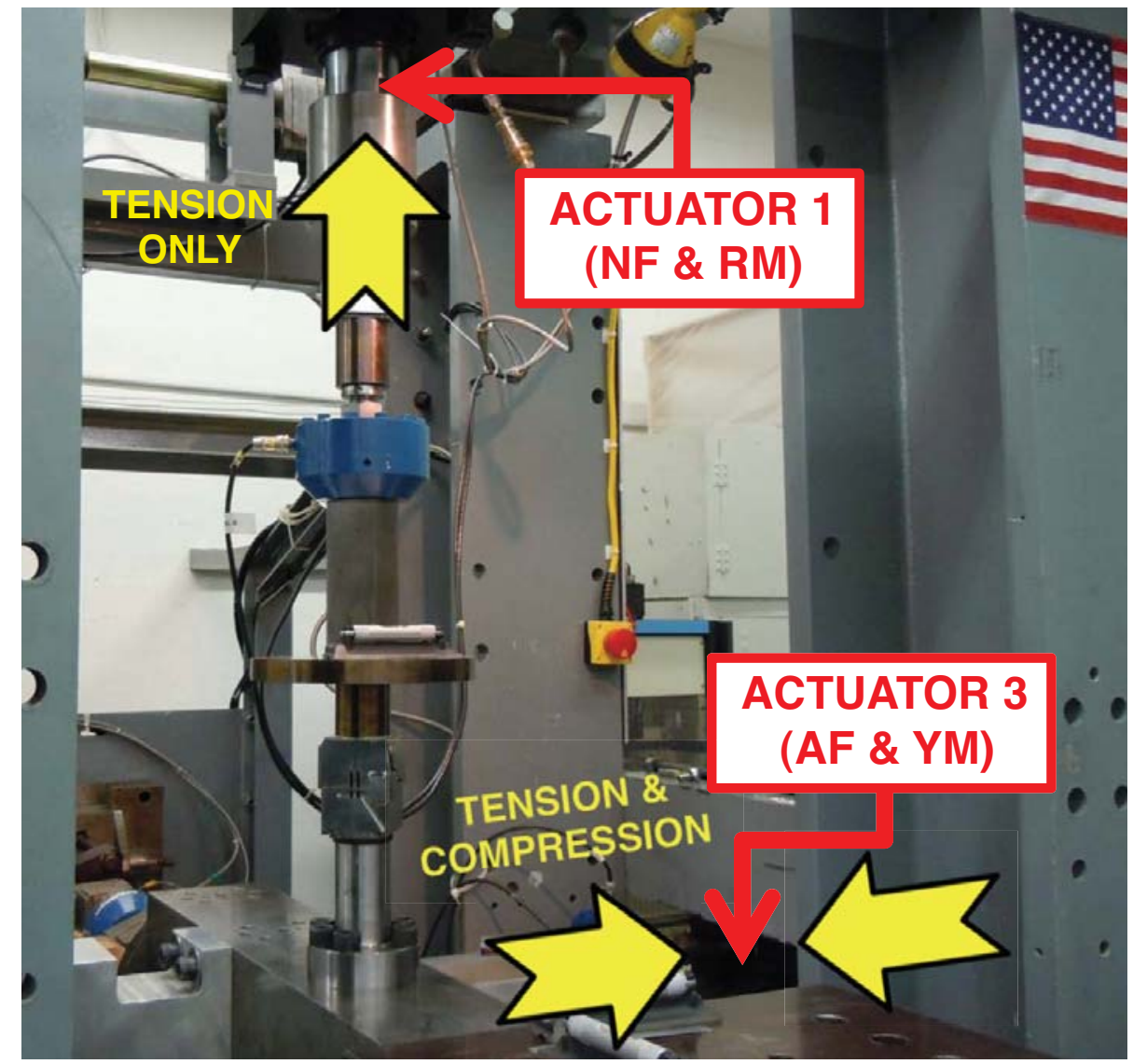

Fig. 13g Installation of hydraulic actuator 3. (Image courtesy of Triumph Aerospace.) 


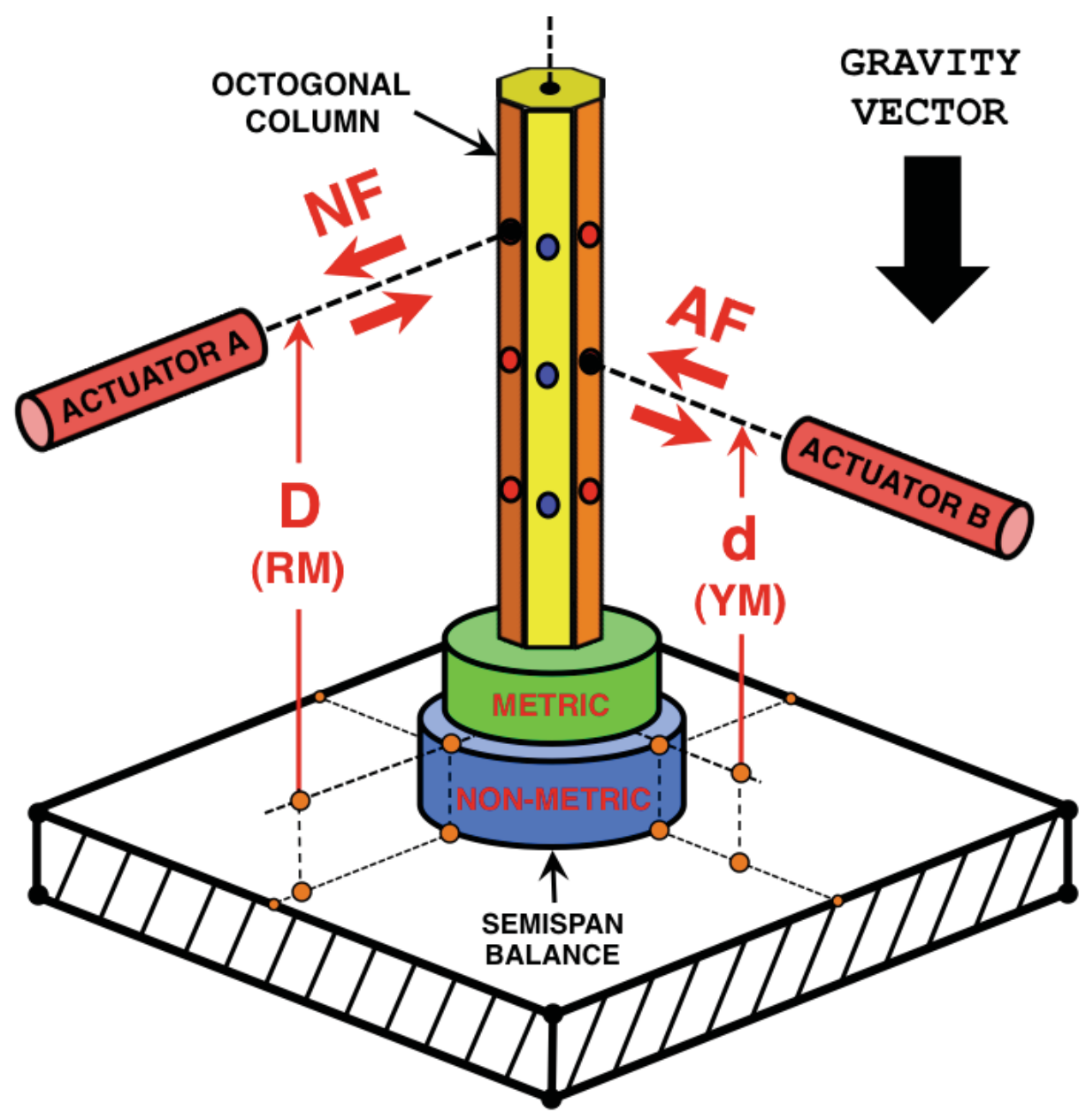

Fig. 14a Hypothetical "tare-load-free" balance calibration rig (application of NF, RM, AF, YM).

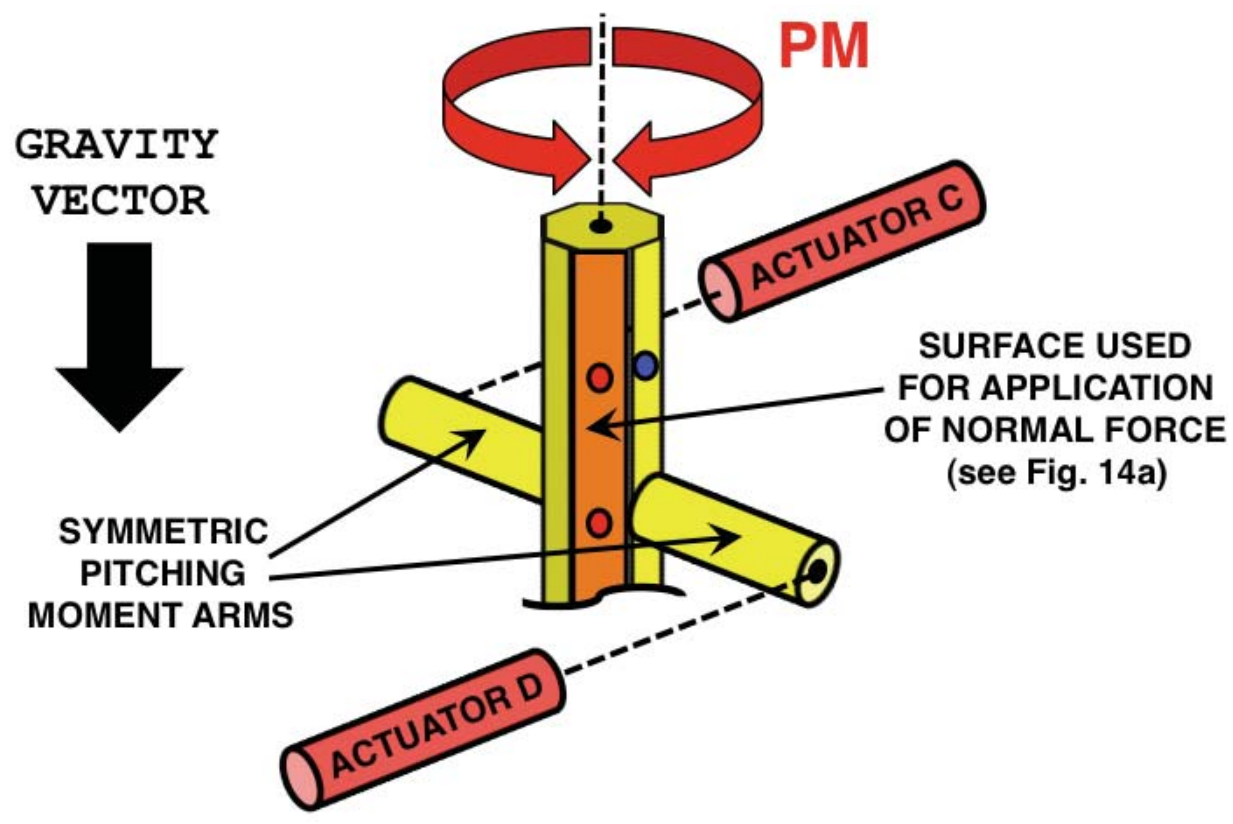

Fig. 14b Hypothetical "tare-load-free" balance calibration rig (application of PM). 
Subject: RE: Final LLR images for review, questions about LLR...

Date: Thursday, February 14, 2013 1:56:33 PM PT

From: Booth, Dennis

To: Ulbrich, Norbert M. (ARC-AOO)[Affiliate]

Hi Norbert,

I will reply in red

The photos are OK to use.

Best Wishes!

\section{Dennis Booth}

Triumph Aerospace Systems -Newport News Inc.

Force Measurement Systems - Manager Operations -

7340 Trade St. Suite D

San Diego CA 92121

Ph 858-537-2020 x-301 Fax 858-537-0720

From: Ulbrich, Norbert M. (ARC-AOO)[Affiliate] [mailto:norbert.m.ulbrich@nasa.gov]

Sent: Thursday, February 14, 2013 11:38 AM

To: Booth, Dennis

Subject: Final LLR images for review, questions about LLR...

Hello Dennis,

Thanks again for the additional image of the LLR. I have included the additional image in the set of images that I plan to use in my paper. Enclosed, please find the final set of images for review and approval. IMPORTANT: I will need another email from you stating that I can use the attached images (I will have to include that email in the official NASA paperwork that I have to file for the paper).

I have a few more questions about the LLR that you should be able to answer:

(1) Was the LLR from the start designed in 1984 to calibrate a five-component semispan balance -or- was the LLR originally designed to calibrate something else and was modified in 1994 so that it could be used to calibrate a semispan balance?

The LLR was originally designed to calibrate other large balances and was modified in 1994 so that it could be used to calibrate a semispan balance?

(2) Positive/Negative Normal Force (NF): The rolling moment arm \& balance have to be physically rotated by 180 deg about the pitch axis of the MC 400 in order to change the sign of the normal force. Is that correct? YES -or- Do you detach the MC400 from the rolling moment arm and rotate only the balance by 180 deg? How do you do it?

The balance and rolling moment arm is rotated 180 to invert and load the opposite direction of $\mathrm{NF}$.

(3) Positive/Negative Pitching Moment (PM): The pitching moment arm has to be detached and afterwards moved/re-attached to the opposite side of the rolling moment arm in order to change the sign of the pitching moment. Is that correct? Yes 
(4) Positive/Negative Axial Force $(\mathrm{AF})$ : The rolling moment arm has to be physically rotated by $180 \mathrm{deg}$ about the pitch axis of the MC400 in order to change the sign of the axial force. Is that correct? Yes

-or- Do you detach the MC400 from the rolling moment arm and rotate only the balance by 180 deg in order to change the sign of the axial force? How do you do it?

The balance and rolling moment arm is rotated 180 to invert and load the opposite direction $\mathrm{NF}$ down for AF loads.

(5) Actuator 1: Actuator 1 (NF) an actuator that only applies a force in one direction (otherwise it would lift the "floating" top of the LLR). Is that correct?

Yes, tension only

(6) Actuator 2: Actuator 2 (PM) an actuator that only applies a force in one direction (because it is not rigidly connected to the floor of the cal lab). Is that correct?

No, the PM actuator loads in both directions. The X-Y table is attached to the plate and the plate is attached to the floor.

(7) Actuator 3: Is actuator $3(\mathrm{AF})$ a tension/compression type actuator -ordoes it only apply a force in one direction? (I cannot tell from the pictures).

Tension and compression

(8) Pitching Moment (PM) \& Axial Force ( $A F)$ : There are situations conceivable when actuator 2 (PM) and actuator 3 ( $A F \& Y M)$ have to be on the same side of the LLR in order to get certain PM/AF sign combinations. In that case, the pitching moment arm is side-by-side to actuator 3 ( $A F$ \& $Y M$ ) and its load chain. I looked at my analysis of the MC400 load schedule and noticed that you seem to have applied those types of combinations. Was that challenging? Did you shift the pitching moment arm sideways in order to get the corresponding set of three yawing moment arms?

The PM arm always mounts on the same side of the LLR, opposite the AF load table.

Both PM and AF actuators can load tension and compression. Both positive and negative loads are generated in both balance upright and inverted orientations. This helps fill in the load combinations.

Thanks in advance for (I) reviewing the final set of images for my paper and (II) your explanation. I am already looking forward to hearing from you.

Have a great day,

Norbert

Norbert Ulbrich, Ph.D.

Senior Aerodynamicist

Jacobs Technology Inc.

NASA Ames Research Center 
$\mathrm{M} / \mathrm{S}$ 227-5

Moffett Field CA 94035-1000

650/604-6893 (phone)

650/604-4357 (fax) 